\title{
DIVISIA MONETARY AGGREGATES FOR THE GCC COUNTRIES ${ }^{1}$
}

\author{
Ryadh M. Alkhareif \\ University of Kansas
}

\author{
William A. Barnett \\ University of Kansas \\ and \\ Center for Financial Stability
}

\begin{abstract}
This paper builds monthly time-series of Divisia monetary aggregates for the Gulf area for the period of June 2004 to December 2011, using area-wide data. We also offer an "economic stability" indicator for the GCC area by analyzing the dynamics pertaining to certain variables such as the dual price aggregates, aggregate interest rates, and the Divisia aggregate user-cost growth rates. Our findings unfold the superiority of the Divisia indexes over the officially published simple-sum monetary aggregates in monitoring the business cycles. There is also direct evidence on higher economic harmonization between GCC countries-- especially in terms of their financial markets and the monetary policy. Monetary policy often uses interest rate rules, when the economy is subject only to technology shocks. In that case, money is nevertheless relevant as an endogenous indicator (Woodford, 2003). Properly weighted monetary aggregates provide critical information to policy makers regarding inside liquidity created by financial intermediaries. In addition, policy rules should include money as well as interest rates, when the economy is subject to monetary shocks as well as technology shocks. The data show narrow aggregates growing while broad aggregates collapsed following the financial crises. This information clearly signals problems with the financial system's ability to create liquidity during the crises.
\end{abstract}

\section{Introduction}

Monetary authorities and economic agencies worldwide find it challenging yet imperative simultaneously to understand and remedy the recent financial crisis. From the

\footnotetext{
1 The authors are appreciative of Mohammed Al-Kheraif's support in providing the GCC data.
} 
perspective of monetary aggregation and index number theory, the increased frequency and severity of financial crises are imputed in part to the misperceptions among economists, financial analysts, and policy makers about the state of the economy. Particularly, evaluating the economy by means of simple-sum monetary aggregates, having no theoretical foundations whatsoever, can lead to erroneous judgments. Instead, economic decisions must be made based upon solid theoretical foundations, using microeconomic theory and statistical index number theory as proposed by Barnett (1978; 1980a,b; and 1981a ). ${ }^{2}$ One such index number is the Divisia index.

Barnett (1978; 1980a,b; and 1981a) created Divisia monetary aggregates by linking microeconomic theory with index number theory. The Divisia monetary index is a money supply measure, which weights the monetary components (e.g., currency, demand deposits, and savings and time deposits) according to their usefulness in transactions. The Divisia index accounts for the variability of the share weights among monetary assets within an aggregate, when measuring the monetary service flows of the economy. The index depends upon prices and quantities of monetary assets, where the price of a monetary asset is called its user cost (rental price).

The foundations of the Divisia monetary index are manifested in its solidarity with microeconomics theory. The index also abides by the classification of superlative index numbers defined by Diewert (1976), since the discrete time Divisia index is exact for the quadratic translog specification of the exact aggregator function. ${ }^{3}$ Thus, the index is a superlative index endowed with a solid theoretical foundation capable of tracking the exact theoretical monetary aggregate of aggregation theory. ${ }^{4}$

The primary purpose of money is threefold: it is a unit of account, a store of value, and a medium of exchange. A key property of Divisia indexes is their ability to remove the investment motive and measure all other monetary services associated with economic liquidity, by allowing the weights of monetary assets to vary depending on their monetary services at the margin [see Hancock (2005) for a more complete discussion]. The Divisia index, unlike its simple-sum counterpart, accounts for the variability of the share weights among monetary assets within an aggregate, when measuring the monetary service flows of the economy. The investment motive is

\footnotetext{
2 See also Barnett's (2012) latest book.

3 Superlative index numbers are exactly correct for a quadratic approximation to the aggregator function. See Barnett (1982) for more details.

4 Although it is true that the Divisia aggregate exactly tracks the true monetary aggregate in continuous time, the discrete time Törnqvist-Theil approximation tracks the true aggregate to second order accuracy.
} 
removed, since otherwise the entire capital stock of the economy would have to be included in the definition of money.

In finance higher returns are often associated with riskier investments, given the rational behavior of investors. Based upon information available at their disposal, investors may choose to invest in low risk assets (e.g., Treasury bills and government bonds) or in riskier assets, such as stocks, options, and other risk-bearing financial instruments. The higher the quality of information and data the investors have, the better qualified they are in making investment decisions. In this regard, Barnett (2012) suggested that inadequate regulations and supervision were not the only factors that caused the subprime financial crisis, but also the low quality of the Federal Reserve published monetary data. Barnett argued that "greed" is an undefined concept in economic theory and instead he points to the defective information provided to the economy by the officially produced simple-sum monetary aggregates, misinforming investors---both individuals and financial institutions---as well as the central bank itself. ${ }^{5}$

The primary pitfall of the simple-sum is its lack of a theoretical foundations. It is a naive index in a sense that it rules out the differences in liquidation and interest-yielding properties of all monetary components (i.e., it implicitly assumes perfect substitutability among monetary assets). The simple-sum is a special case of the Divisia monetary aggregates under the unrealistic assumption that monetary assets are perfectly substitutable for one another. However, money currently encompasses monetary assets with different positive rates of returns. As a result, perfect substitutability among assets within an aggregate is no longer a valid assessment. Simple-sum indexes, as pointed out by Barnett (1980b), provide invalid structural economic variables. This assessment advocates for using indexes which measure structural economic variables, as is the subject of index number theory and its associated aggregation theory.

Barnett (1981b, p. 488) comments on the unsatisfactory simple-sum and advocates a formally derivable monetary index:

\begin{abstract}
"Simple-sum aggregates do not and cannot accurately indicate the quantity of monetary services being provided to the economy. Properly constructed quantity index numbers can. Monetary aggregates should be no less competently constructed than aggregates long available for other
\end{abstract}

\footnotetext{
${ }^{5}$ For more complete discussion, see Barnett's (2012) latest book.
} 
economic variables, such as commodity quantities or prices."

The remainder of this paper is organized as follows: section 2 provides a summary of the seminal theoretical considerations relating to the Divisia monetary aggregates; section 3 constructs Divisia monetary aggregates for the GCC countries and builds a common Divisia index for the GCC area; section 4 discusses the Divisia second moments and the distribution effects; section 5 comprises the conclusion.

\section{The Theory of Divisia Monetary Aggregation}

While aggregation and index number theory are highly developed in the fields of consumer demand theory and production theory, they were not applied to monetary theory until Barnett (1978, 1980a,b) derived the correct formula of the price (user cost) of monetary assets and thereby produced a connection between monetary economics and index number theory. User cost is the interest return forgone by holding a monetary asset rather than holding highest return (usually less-liquid) asset. The user cost of money is its opportunity cost and thereby the price of a monetary asset. The seminal work of Barnett (1978; 1980a,b; and 1987) derived the Jorgensonian user cost of monetary assets from a rigorous Fisherine intertemporal consumption expenditure allocation model. His findings have inaugurated the use of index number theory into monetary economics.

The current period nominal user cost of monetary asset $i$, having quantity $m_{i t}$ during period $t$, is ${ }^{6}$

$$
\pi_{i t}=p_{t}^{*} \frac{R_{t}-r_{i t}}{1+R_{t}}
$$

where

$R_{t}$ is the benchmark rate at time $t$.

$r_{i t}$ is the rate of return on asset $i$ during $t$.

$p_{t}^{*}$ is the true cost-of-living index price at time $t$.

${ }^{6}$ The real and nominal user-cost prices are related to one another by the following direct relationship: $\pi_{i t}=p_{t}^{*}$ $\pi_{i t}^{*}$. 
The user cost nets out the investment motive of holding money, so that the quantity index measures all other serves of the monetary assets. The vector of user-cost prices is $\boldsymbol{\pi}_{t}$ and the vector of corresponding nominal monetary asset quantities is $\mathbf{m}_{t}$, while is the vector of real quantities is $\mathbf{m}_{t}^{*}=\mathbf{m}_{t} / p_{t}^{*}$.

The Divisia price and quantity indexes solve the following dual differential equations for the price aggregate, $\Pi_{t}=\Pi\left(\boldsymbol{\pi}_{t}\right)$, and the monetary quantity aggregate, $M_{t}=M\left(\mathbf{m}_{t}\right)$, respectively:

$$
\begin{gathered}
\frac{d \log \Pi_{t}}{d t}=\sum_{i} s_{i t} \frac{d \log \pi_{i t}}{d t}=\sum_{i}\left(\frac{\pi_{i t} m_{i t}}{\sum_{k=1}^{N} \pi_{k t} m_{k t}}\right) \frac{d \log \pi_{i t}}{d t} \\
\frac{d \log M_{t}}{d t}=\sum_{i} s_{i t} \frac{d \log m_{i t}}{d t}=\sum_{i}\left(\frac{\pi_{i t} m_{i t}}{\sum_{k=1}^{N} \pi_{k t} m_{k t}}\right) \frac{d \log m_{i t}}{d t}
\end{gathered}
$$

where $s_{i t}=\frac{\pi_{i t} m_{i t}}{\sum_{k=1}^{N} \pi_{k t} m_{k t}}$ is the expenditure share for the $i^{t h}$ monetary asset during period $t$.

The discrete time representation of the Divisia index is needed for empirical applications, since economic data are measured in discrete time. Törnqvist (1936) and Theil (1967) proved that the Törnqvist-Theil approximation is a second order approximation to the continuous time Divisia index. At time $t$, the discrete time representation of the Divisia price index, $\Pi_{t}$, over user-cost prices and the Divisia quantity index, $M_{t}$, over the monetary components respectively are: $^{7}$

$$
\log \Pi_{t}-\log \Pi_{t-1}=\sum_{i=1}^{N} s_{i t}^{*}\left(\log \pi_{i t}-\log \pi_{i, t-1}\right)
$$

\footnotetext{
7 Törnqvist-Theil approximation, which is the Simpson's rule approximation, is commonly used to approximate the Divisia index. See Barnett (1987) for more details.
} 


$$
\log M_{t}-\log M_{t-1}=\sum_{i=1}^{N} s_{i t}^{*}\left(\log m_{i t}-\log m_{i, t-1}\right)
$$

where $s_{i t}^{*}=(1 / 2)\left(s_{i t}+s_{i, t-1}\right)$, is the average of the current and lagged expenditure shares $s_{i t}$ and $s_{i, t-1}$.

Equations (4) and (5) are the weighted averages of the growth rates of user-cost prices, $\boldsymbol{\pi}_{t}$, and monetary components, $\mathbf{m}_{t}$, at time $t$, respectively. In levels, the Divisia monetary index $M_{t}$ can be written as:

$$
\frac{M_{t}}{M_{t-1}}=\prod_{i=1}^{n}\left(\frac{m_{i t}}{m_{i, t-1}}\right)^{s_{i t}^{*}},
$$

which is known as the Törnqvist-Theil Divisia monetary quantity index.

Dual to the quantity index, $M_{t}$, there is the aggregate price index $\Pi_{t}$, which equals the total expenditue on monetary components divided over the quantity monetary aggregate. ${ }^{8}$ More formally,

$$
\Pi_{t}=\frac{\sum_{i=1}^{N} \pi_{i t} m_{i t}}{M_{t}}
$$

where equation (6) satisfies Fisher's factor reversal test:

$$
\Pi_{t} M_{t}=\sum_{i=1}^{N} \pi_{i t} m_{i t}
$$

The Divisia, Paasche, and Laspeyres indexes are not self-dual. As a result, equations (4) and (6) do not produce exactly the same price aggregate. But the remainder term between them is third order in the changes, and typically less than the roundoff error in the component data. ${ }^{9}$

\section{Constructing a GCC Area Divisia Monetary Aggregate}

A large number of countries maintain Divisia monetary aggregates. While some central banks make these indexes available to the public, many central banks provide and use them only internally. Monetary authorities supplying Divisia monetary aggregates internally or publicly

\footnotetext{
${ }^{8}$ The quantity index $M_{t}$ and price index $\Pi_{t}$ result from the duality theory under linear homogeneity. Barnett (1987) extended the derivation of the quantity index and price index to the nonhomogeneous case.

9 See Barnett (1982) for a rigorous discussion on this subject. For nonmathematical explanations, see Barnett (2012).
} 
include the Federal Reserve Bank of St. Louis, the European Central Bank, the Bank of England, the Bank of Japan, the Bank of Israel, the National Bank of Poland, and the International Monetary Fund (IMF). ${ }^{10}$ While many studies have produced Divisia monetary aggregates data for countries worldwide, there are no Divisia data available for the complete GCC area. ${ }^{11}$

The scarcity of GCC monetary data has limited researchers from exploring and investigating the influence of Divisia aggregation on GCC monetary policy analyses. This paper reports on the first Divisia monetary aggregates for the complete GCC area and focuses on economic measurement. Issues related to utility function specifications, parameter estimation, and other econometric applications were avoided. ${ }^{12}$ Hence, our reesults are unbiased in the sense that they involve no estimations or inferences at all. We let the data speak for themselves.

Further research can make use of techniques used by the literature on the European Monetary Union (EMU). This literature, highly relevant to the GCC area, includes: Barnett (2003, 2007), Binner, Bissoondeeal, Elger, Gazely, and Mullineux (2005), Binner, Bissoondeeal, Elger, Jones, and Mullineux (2009), Binner, Gazely, and Kendall (2008), Reimers (2002), Stracca (2001), and Beyer, Doornik and Hendry (2000).

Our Divisia monetary indexes for the Gulf States can not only provide the Gulf central banks with a wider range of tools, but also can serve as a vehicle for researchers to improve studies on Gulf monetary policy. Our findings are in line with the those in Barnett (2012) and Barnett and Chauvet (2011a,b), in which the discrepancy between Divisia and simple-sum growth rates widened during times of high uncertainty and periods of economic disruptions, such as the financial turmoil. Interestingly, the narrow aggregates were growing while broad aggregates collapsed following the financial crises. This information clearly signals problems with the financial system's ability to create liquidity during the crises.

\subsection{Data Descriptions and Sources}

\footnotetext{
10 The Center for Financial Stability (CFS) in New York City provides a directory on the literature pertaining to Divisia monetary aggregations for over 40 countries throughout the world. For more information on Divisia monetary aggregates, visit the CFS website at www.centerforfinancialstability.org/amfm.php.

11 To date, Alsahafi (2009) is the only paper producing Divisia indexes for a GCC country, and that paper's results are limited to Saudi Arabia.

12 Parametric specifications needed for estimating aggregator functions could hinder the objectivity of the data. Index number theory is not dependent upon such specifications. See Barnett (2012) for more details pertaining to monetary aggregation theory and statistical index numbers.
} 
The six GCC countries---Bahrain, Kuwait, Oman, Qatar, Saudi Arabia, and United Arab Emirates--are the sample countries of this chapter. Variables taken into consideration in the calculation of the Divisia monetary aggregates include: currency in circulation, overnight deposits, demand deposits, savings and time deposits, quasi-money, overnight deposit rates, rate of return on demand deposits, interest rates on savings and time deposits, Treasury bills rates of return, and interest rates on short-term loans. The domestic short-term loan rate is usually the highest and hence used as the benchmark rate for most periods.

The analysis in this study is based on monthly data starting as far as the data were available and ending in December 2011. The GCC central banks are the main sources of monetary data. Interest rates and other monetary data were extracted from the International Financial Statistics (IFS), Federal Reserve Economic Data (FRED), Bloomberg database, and the GCC Secretariat General.

All quantities have been seasonally adjusted using X11 procedure. There were not many missing data in our study. We applied moving average interpolation, whenever data were missing. Conversion from total to per-capita values requires population data, which are only available with annual frequency. To acquire monthly population series, we use linear interpolation.

When used with simple-sum monetary quantity aggregation, the inflation rates for the aggregated Gulf area could be computed as the arithmetic averages of the GCC countries' corresponding inflation rates, to be consistent with the implicit assumption of perfect substitutability embeded in simple-sum quantity aggregation. If willing to make the unreasonable assumption of perfect substitutability among monetary asset quantities, why not be philosophically consistent and make the same unreasonable assumption about consumer goods? But when used with the Divisia monetary quantity indexes, we use Divisia price aggregation over countries.

\subsection{Benchmark Rate of Return for the GCC Countries}

Within the field of aggregation and index number theory, the benchmark rate plays a pivotal role in constructing the Divisia index, since the benchmark rate appears in the user-cost formula for all monetary assets. Barnett (1987) defined the benchmark rate, $R_{t}$, to be the yield on a pure investment asset, held solely to accumulate wealth and providing no other services, such as liquidity. The benchmark rate is the interest rate on a theoretical asset held only to 
transfer wealth over multiperiod planning horizons. During each period, our proxy for the theoretical benchmark rate is the highest rate attained among all relevant assets on which we have data, such as the interest rates on demand deposits, savings and time deposits, loans, government bonds, and Treasury bills. In other words, the benchmark rate, in each period of time, is the maximum rate attained over a set of rates pertaining to monetary assets and other monetary instruments, such as Treasury bills and short-term loans. ${ }^{13}$

In mathematical representation, our benchmark rate takes the following form:

$$
R_{t}=\operatorname{Max}\left\{r_{i, t}, r_{\text {bills,t }}, r_{\text {loan,t }}, r_{\text {interbank,t }}\right\},
$$

where,

$$
\begin{aligned}
& r_{i t} \text { is the rate of return on asset } i \text { during period } t, \\
& r_{\text {bills,t }} \text { is the interest rate on Treasury bills at time } t, \\
& r_{\text {loan, },} \text { is the loan interest rate at time } t, \\
& r_{\text {interbank,t }} \text { is the interbank interest rate at time } t .
\end{aligned}
$$

\subsection{Divisia Monetary Aggregates Within GCC Countries}

Within country Divisia monetary indexes are computed for the GCC countries. We follow the theory provided by Theil (1967) and Barnett (1979a,b; 1980b) and extended in Barnett $(2003,2007)$ to multilateral aggregation permitting aggregation within and then over countries. The approach uses economic index number theory and assumes the existence of a representative agent within each country. We begin by presenting the theory in continuous time, before converting to discrete time.

Let $K$ be the number of countries in the Gulf Monetary Union. For each country $k \in\{1, \ldots, K\}$, define the true cost-of-living index as $p_{k}^{*}=p_{k}^{*}\left(\boldsymbol{p}_{k}\right)$, where $\boldsymbol{p}_{k}=\boldsymbol{p}_{k}(t)$ represents the vector of prices of consumer goods at time $t .{ }^{14}$ Let $\mathbf{x}_{k}=\mathbf{x}_{k}(t)$ be the vector of per-capita real rates of consumption of those goods in country $k$ at time $t$. Let $m_{k j i}$ and $r_{k j i}$ be,

\footnotetext{
13 This is called the "envelope approach." See Barnett, Offenbacher, and Spindt (1984) for a complete discussion of this methodology.

14 The theoretical true cost-of-living index is derived from aggregation theory and contains only prices whereas the Consumer Price Index (CPI) formula includes prices and quantities. The CPI is derived from statistical index number theory to approximate the true cost-of-living index nonparametrically [see, e.g., Barnett $(2003,2012)$ for further discussion].
} 
respectively, the nominal per-capita holdings and the yields on asset type $i, i \in\{1, \ldots, N\}$, purchased in country $j$ and owned by individual(s) in country $k$. We enable economic agents within the Gulf area to hold assets in $\mathrm{Z}$ outside countries. Moreover, let $N_{j}$ be the number of different asset types that can be held in country $j$ and let $N$ be the total number of asset types available within all of the relevant countries, $j \in\{1, \ldots, K+Z\} .{ }^{15}$ Finally, let $R_{k}=R_{k}(t)$ and $H_{k}=H_{k}(t)$ be the benchmark rate of return and the population of country $k$ at time $t$, respectively. Hence, the real user-cost price of asset $i$ purchased in country $j$ and owned by economic agent(s) of country $k$ at time $t$ is ${ }^{16}$

$$
\boldsymbol{\pi}_{k j i}^{*}(t)=R_{k}(t)-r_{k j i}(t)
$$

In line with the economic approach proposed by Barnett (1980a,b; 1987), we assume weak separability and linearly homogeneity of the representative agent's utility function $u_{t}{ }^{17}$ We use the following formal notations:

Let

$$
\begin{aligned}
\mathbf{m}_{k j}^{*} & =\left(m_{k j 1}^{*}, \ldots, m_{k j i}^{*}, \ldots, m_{k j N}^{*}\right)^{\prime} \\
\mathbf{m}_{k j} & =\left(m_{k j 1}, \ldots, m_{k j i}, \ldots, m_{k j N}\right)^{\prime} \\
\boldsymbol{\pi}_{k j}^{*} & =\left(\pi_{k j 1}^{*}, \ldots, \pi_{k j i}^{*}, \ldots, \pi_{k j N}^{*}\right)^{\prime} \\
\boldsymbol{\pi}_{k j} & =\left(\pi_{k j 1}, \ldots, \pi_{k j i}, \ldots, \pi_{k j N}\right)^{\prime} \\
\mathbf{r}_{k j} & =\left(r_{k j 1}, \ldots, r_{k j i}, \ldots, r_{k j N}\right)^{\prime}
\end{aligned}
$$

and let

$$
\begin{aligned}
\mathbf{m}_{k}^{*} & =\left(\mathbf{m}_{k 1}^{*}, \ldots, \mathbf{m}_{k j}^{*}, \ldots, \mathbf{m}_{k, K+Z}^{*}\right)^{\prime} \\
\mathbf{m}_{k} & =\left(\mathbf{m}_{k 1}, \ldots, \mathbf{m}_{k j}, \ldots, \mathbf{m}_{k, K+Z}\right)^{\prime} \\
\boldsymbol{\pi}_{k}^{*} & =\left(\boldsymbol{\pi}_{k 1}^{*}, \ldots, \boldsymbol{\pi}_{k j}^{*}, \ldots, \boldsymbol{\pi}_{k, K+Z}^{*}\right)^{\prime} \\
\boldsymbol{\pi}_{k} & =\left(\boldsymbol{\pi}_{k 1}, \ldots, \boldsymbol{\pi}_{k j}, \ldots, \boldsymbol{\pi}_{k, K+Z}\right)^{\prime}
\end{aligned}
$$

\footnotetext{
15 Clearly $N \geq N_{j}$ for all $j \in\{1, \ldots, K+Z\}$.

16 The real and nominal user-cost prices are related to one another as follows: $\boldsymbol{\pi}_{k j i}(t)=P_{k}^{*}(t) \boldsymbol{\pi}_{k j i}^{*}(t)$.

17 Barnett (1987) incorporated the nonhomothetic case to aggregation and index number theory. Under the nonhomogeneous case, the Divisia index is uniquely considered to be the best element of Diewert's superlative class.
} 


$$
\mathbf{r}_{k}=\left(\mathbf{r}_{k 1}, \ldots, \mathbf{r}_{k j}, \ldots, \mathbf{r}_{k, K+Z}\right)^{\prime}
$$

Our computations are restricted, whenever applicable, to the index set: $S_{k}=\left\{(j, i): m_{k j i}>0, \quad j \in\{1, \ldots, K+Z\}, i \in\{1, \ldots, N\} \quad\right.$ for all $k \in\{1, \ldots, K\}$.

Following Barnett (2003), our Divisia indexes for the Gulf countries can be defined as follows: within each country, $k \in\{1, \ldots, K\}$, the real per-capita monetary services aggregate, $M_{k}^{*}$, the nominal per-capita monetary services aggregate, $M_{k}$, the real user-cost price aggregate, $\Pi_{k}^{*}$, and the nominal user-cost price aggregate, $\Pi_{k}$, respectively are:

$$
\begin{aligned}
& d \log M_{k}^{*}=\sum_{(j, i) \in S_{k}} w_{k j i} d \log m_{k j i}^{*} \\
& d \log M_{k}=\sum_{(j, i) \in S_{k}} w_{k j i} d \log m_{k j i} \\
& d \log \Pi_{k}^{*}=\sum_{(j, i) \in S_{k}} w_{k j i} d \log \pi_{k j i}^{*} \\
& d \log \Pi_{k}=\sum_{(j, i) \in S_{k}} w_{k j i} d \log \pi_{k j i}
\end{aligned}
$$

where,

$$
w_{k j i}=\frac{\pi_{k j i} m_{k j i}^{*}}{\boldsymbol{\pi}_{k} \mathbf{m}_{k}^{*}}=\frac{\pi_{k j i}^{*} m_{k j i}^{*}}{\boldsymbol{\pi}_{k}^{*} \mathbf{m}_{k}^{*}}=\frac{\left(R_{k}-r_{k j i}\right) m_{k j i}^{*}}{\sum_{(j, i) \in S_{k}}\left(R_{k}-r_{k j i}\right) m_{k j i}^{*}}=\frac{\left(R_{k}-r_{k j i}\right) m_{k j i}}{\sum_{(j, i) \in S_{k}}\left(R_{k}-r_{k j i}\right) m_{k j i}} .
$$

Notice that $0 \leq w_{k j i} \leq 1$ for all $k \in\{1, \ldots, K\}, j \in\{1, \ldots, K+Z\}$, and $i \in\{1, \ldots, N\}$. Moreover, $\sum_{(j, i) \in S_{k}} w_{k j i}=1$ for all $k \in\{1, \ldots, K\}$ implies that the shares, $w_{k j i}$, possess the properties of a probability distribution for each country $k \in\{1, \ldots, K\}$. Consequently, the above Divisia indexes could be interpreted as Divisia growth rate means. ${ }^{18}$

The equivalent discrete time representation of the above continues time Divisia indexes are, respectively:

\footnotetext{
18 This is a statistical representation of the Divisia growth rate means. See Barnett (2003) for an alternative representation.
} 


$$
\begin{aligned}
\log M_{k t}^{*}-\log M_{k, t-1}^{*} & =\sum_{(j, i) \in S_{k}} w_{k j i t}^{*}\left(\log m_{k j i t}^{*}-\log m_{k j i, t-1}^{*}\right) \\
\log M_{k t}-\log M_{k, t-1} & =\sum_{(j, i) \in S_{k}} w_{k j i t}^{*}\left(\log m_{k j i t}-\log m_{k j i, t-1}\right) \\
\log \Pi_{k t}^{*}-\log \Pi_{k, t-1}^{*} & =\sum_{(j, i) \in S_{k}} w_{k j i t}^{*}\left(\log \pi_{k j i t}^{*}-\log \pi_{k j i, t-1}^{*}\right) \\
\log \Pi_{k t}-\log \Pi_{k, t-1} & =\sum_{(j, i) \in S_{k}} w_{k j i t}^{*}\left(\log \pi_{k j i t}-\log \pi_{k j i, t-1}\right),
\end{aligned}
$$

where $w_{k j i t}^{*}=\frac{\left(w_{k j i t}+w_{k j i, t-1}\right)}{2}$.

In levels, the real and nominal per-capita Divisia monetary indexes, respectively, are

$$
\frac{M_{k t}^{*}}{M_{k, t-1}^{*}}=\prod_{(j, i) \in S_{k}}\left(\frac{m_{k j i t}^{*}}{m_{k j i, t-1}^{*}}\right)^{w_{k j i t}^{*}}
$$

and

$$
\frac{M_{k t}}{M_{k, t-1}}=\prod_{(j, i) \in S_{k}}\left(\frac{m_{k j i t}}{m_{k j i, t-1}}\right)^{w_{k j i t}^{*}} .
$$

By Fisher's factor reversal test, there exists a user-cost price aggregate dual to the exact service quantity aggregate such that their product equals the total expenditure on the components. More formally,

$$
\Pi_{k t} M_{k t}=\sum_{(j, i) \in S_{k}} \pi_{k j i t} m_{k j i t},
$$

The exact user-cost aggregate price dual to the exact quantity aggregate is thereby obtained by dividing actual expenditure on the components by the quantity aggregate, as follows:

$$
\Pi_{k t}=\frac{\sum_{(j, i) \in S_{k}} \pi_{k j i t} m_{k j i t}}{M_{k t}} .
$$

The literature on interest rate aggregation is different from the literature relevant to economic aggregation and index-number theory. Unlike user-cost aggregation, which is a form of price aggregation, interest rate aggregation is based on elementary accounting principles. Let $\tilde{R}_{k t}$ 
be country $k$ 's aggregate interest rate at time $t$. A portfolio of monetary assets $\left\{\boldsymbol{m}_{k t}:(j, i) \in S_{k}\right\}$ with interest rates $\left\{\boldsymbol{r}_{k t}:(j, i) \in \mathrm{S}_{\mathrm{k}}\right\}$ has investment yield $\sum_{(j, i) \in S_{k}} r_{k j i t} m_{k j i t}$. Hence, the following accounting identity must hold, in order for $\widetilde{R}_{k t}$ to be the rate of return on the portfolio :

$$
\tilde{R}_{k t} \sum_{(j, i) \in S_{k}} m_{k j i t}=\sum_{(j, i) \in S_{k}} r_{k j i t} m_{k j i t} .
$$

Solving for $\widetilde{R}_{k t}$, we acquire

$$
\tilde{R}_{k t}=\frac{\sum_{(j, i) \in S_{k}} r_{k j i t} m_{k j i t}}{\sum_{(j, i) \in S_{k}} m_{k j i t}}
$$

This paper defines Divisia monetary aggregates in GCC countries as following: the narrowed Divisia monetary aggregate, D1, will contain both currency in circulation and demand deposits. As in M2, the broader Divisia monetary aggregate, D2, will include D1 plus savings and time deposits. The central bank of Qatar, in turn, incorporates quasi-money within the broader monetary aggregates. Consequently, the Divisia monetary aggregates will be slightly different for Qatar relative to the others. ${ }^{19}$

Figure 1 contains plots of the year-over-year growth rates of the narrow Divisia and simple-sum monetary aggregates for the GCC countries. The two approaches to aggregation produce identical results, since all assets within the monetary aggregates bear zero-interest rates and therefore have the same user-cost prices. $^{20}$ Specifically, currency in circulation and demand deposits are zero-interest assets, and hence the theory implies that consumers are indifferent between those two assets. ${ }^{21}$

\footnotetext{
19 The inclusion of the quasi-money in the broader monetary aggregate is based solely on data availability.

20 The interest rates on demand deposits in Qatar offer positive interest rates. Since demand deposits' interest rates are low, while the benchmark rates are exceptionally high, the user-cost prices of currency in circulation and demand deposits are relatively similar.

21 Some papers impute an implicit rate of return on demand deposits [see, e.g., Klein (1974) and Startz (1979)]. Alsahafi (2009) constructed Divisia monetary index for Saudi Arabia with an implicit rate of return imputed to demand deposits. Nevertheless, given the fact that there is neither public data nor solid evidence on such an imputation, we exclude implied interest rates on demand deposits.
} 
Figure 1: Year-Over-Year Growth Rates of the Divisia and Simple-Sum Monetary Aggregates, M1 (annual percentage change)
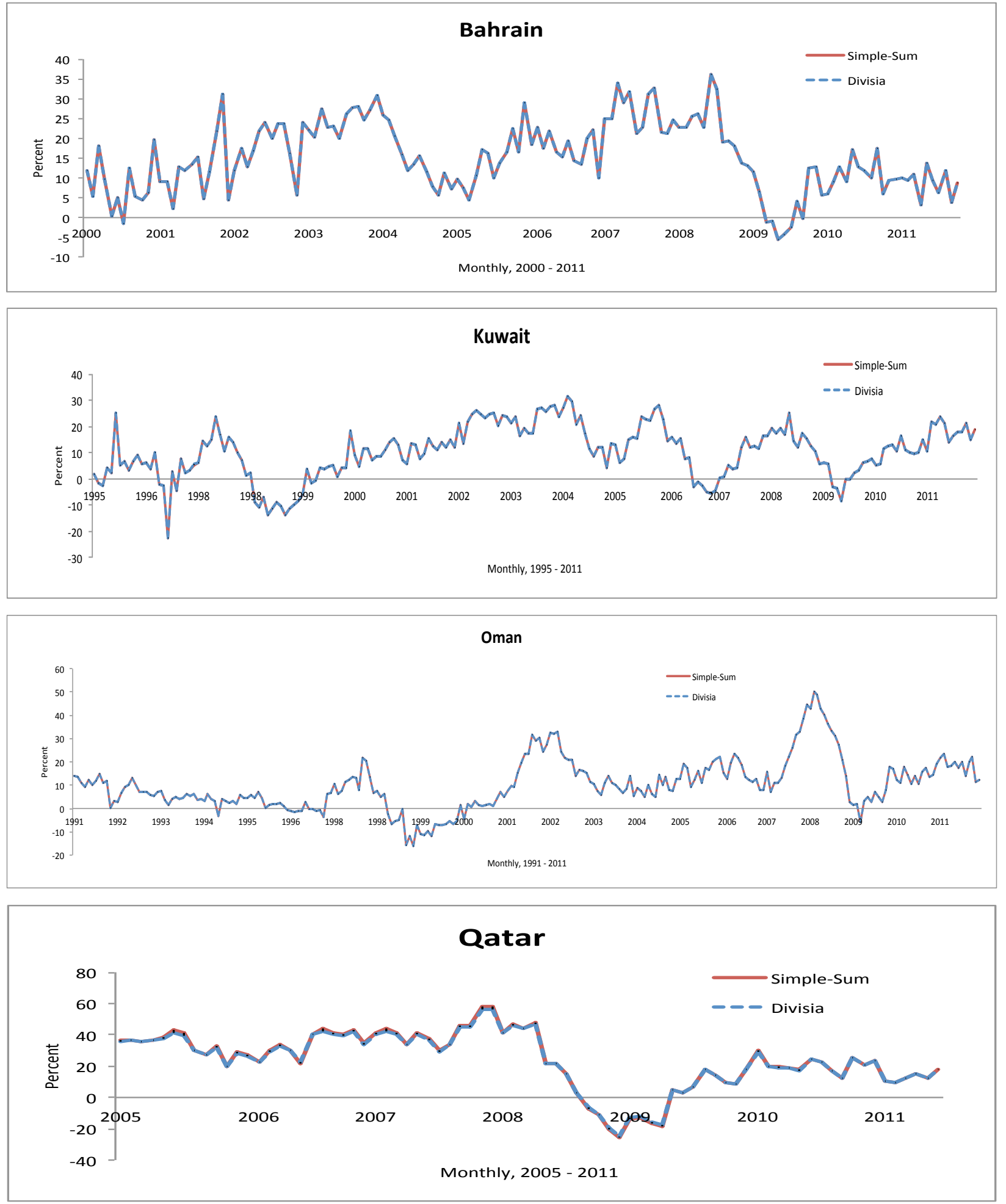

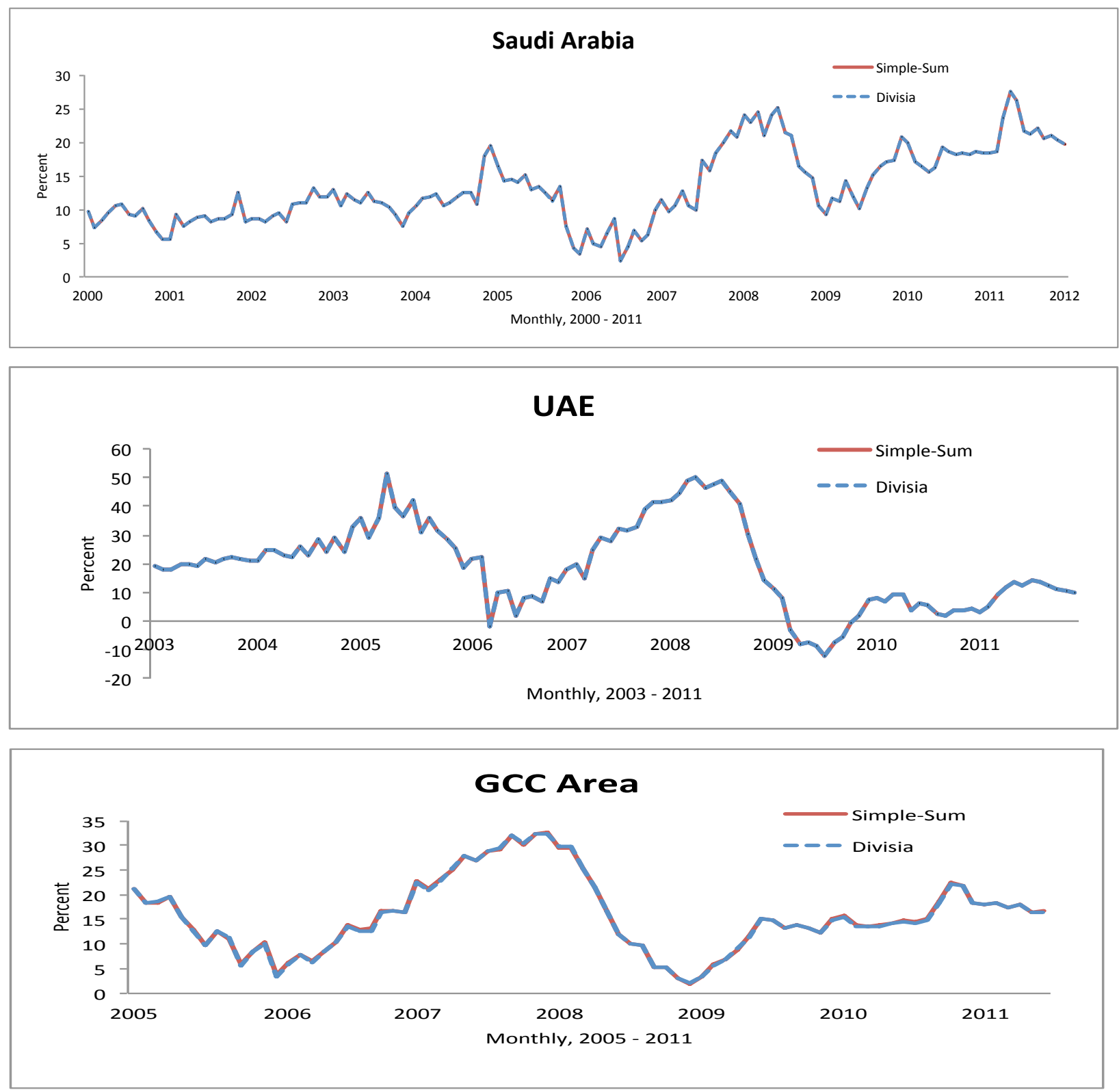

By construction, broad monetary aggregates contain assets with positive interest rates. Assuming perfect substitutability among assets yielding different interest rates is not permissible. ${ }^{22}$ For most countries (and the GCC as a whole) the imperfect substitutability among those assets leads to distinct results between Divisia and simple-sum aggregates - suggesting that policy makers may reach different conclusions based on the different aggregation procedures.

Figure 2 displays the year-over-year growth rates of the broad Divisia and simple-sum monetary aggregates for the GCC countries. The most interesting charts are reported for Kuwait

\footnotetext{
22 Perfect substitutability among assets exists, if and only if, all assets within an aggregate offer the same rate of return.
} 
and Saudi Arabia, where the year-over-year growth rates for the broad Divisia and simple-sum aggregates interchangeably shift over time. For instance, in Kuwait there has been a rotation between the year-over-year growth rates of the broad Divisia and simple-sum. Divisia growth rates fluctuate from being above simple-sum during mid 2000 to mid 2004 and to being below from early 2006 to late 2007 . The broad Divisia growth rates diverge from simple-sum as a result of the high variation in the user costs of the monetary components. This variation suggests that monetary assets in Kuwait are less substitutable. The Divisia indexes fall sharply as the demand deposits (called sight deposits) in Kuwait spiked in mid-1995 from being 823.4 million in May up to 1081.5 and then fell back to 810.3 in July. Divisia indexes were able to signal such economic disruptions in the monetary system. 
Figure 2: Year-Over-Year Growth Rates of the Divisia and Simple-Sum Monetary Aggregates, M2 (annual percentage change)
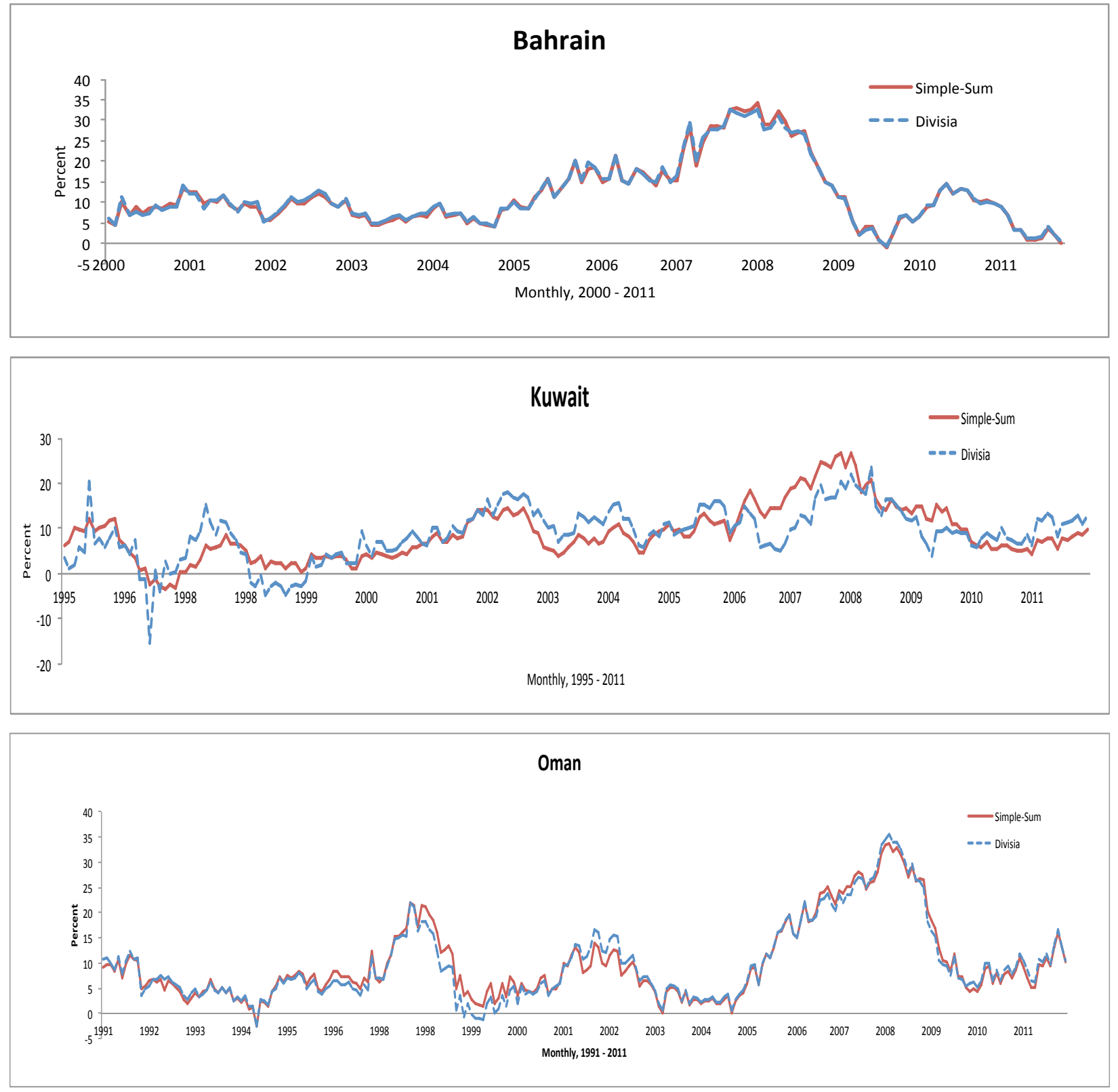

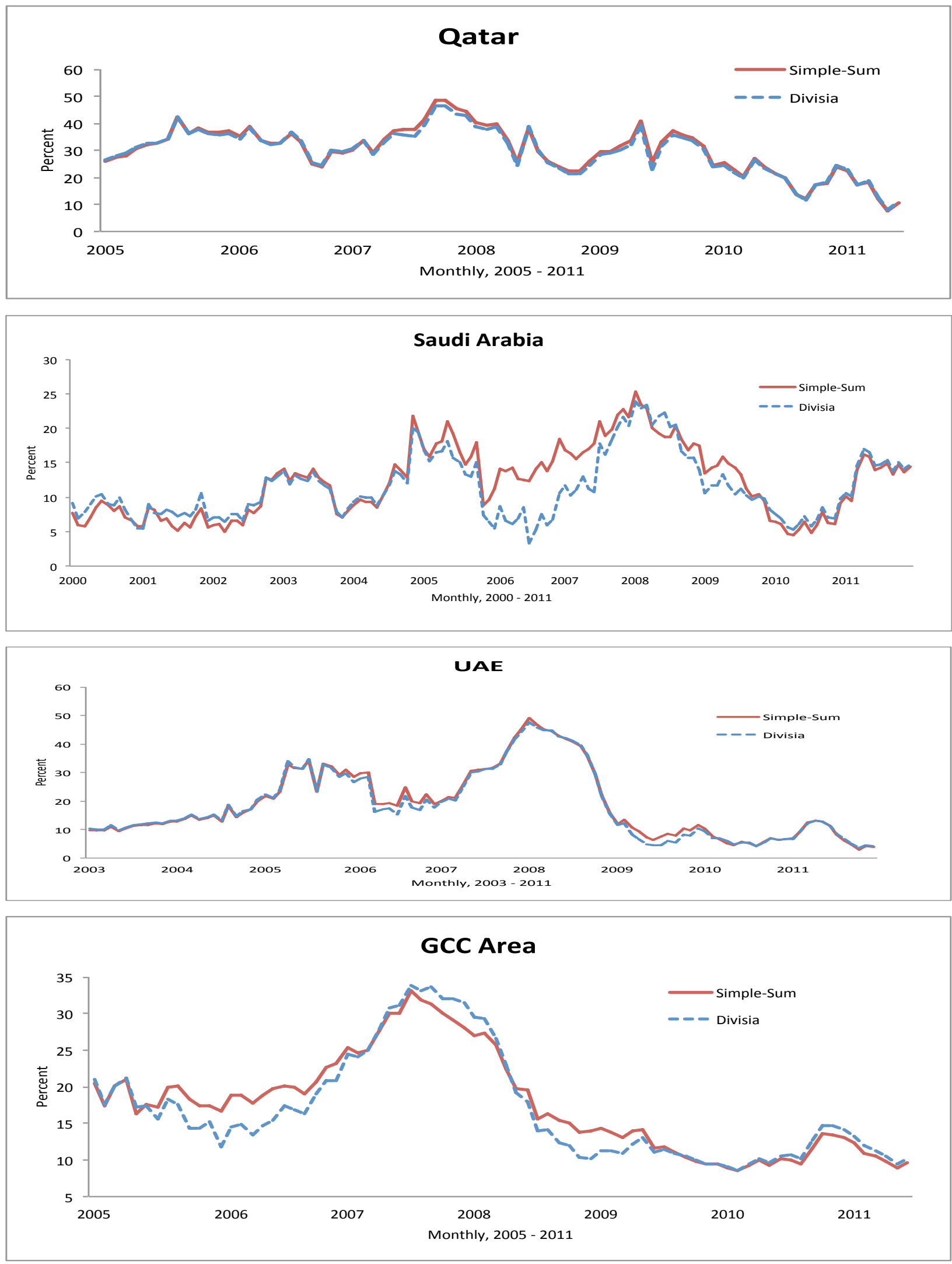
The Saudi capital market plunged in 2006. Specifically, the Saudi stock market meltdown in 2006 was accurately captured by the Divisia monetary indexes, in which the year-over-year growth rates for Divisia fell sharply during the first six months of 2006 to almost zero percent and bounced up to reach its maximum in early 2008 (figure 2 ).$^{23}$ During the recent financial crisis, the Divisia growth rate fluctuated from being above simple-sum in late 2008 to being below in early 2009. This result indicates that the monetary policy was more contractionary than likely intended during the financial crisis, when the Divisia monetary aggregates growth rates were lower than their simple-sum counterparts.

In 1998, when the price of oil dropped and reached minimum levels (approximately $\$ 10$ per barrel) for more than two decades, thereby adversely affecting the domestic economy, the Omani monetary policy endeavored to stabilize the economy. ${ }^{24}$ This led to a one-year hiatus between the year-over-year growth rates of Divisia and simple-sum (figure 2).

In Bahrain, steady growth prevailed from 2000 to 2005, but the year-over-year monetary growth accelerated afterwards to attain its peak in early 2008, in response to the boom of oil prices (figure 2). However, the growth fell sharply in mid-2008, as a result of the sudden drop of energy prices. The recently erupted demonstrations and civil uprisings, called the "Arab Spring", during which the Bahraini government has declared a three-month state of emergency, have hindered economic reintegration.

In Qatar, the growth rates of the narrow monetary aggregate are fairly stable except in late 2008 when demand for deposits witnessed a transitory decline (more than 20\%). The year-over-year growth rates reveal a downward trend from mid-2008 to 2009, during which the Qatari central bank aimed to subdue staggering inflation (figure 1). Similarly, the growth rates for the broader aggregates illustrate the central banks effort in deflating the economy as plotted in figure 2 .

The openness of the UAE economy has made the country more vulnerable to the financial crisis. During the crisis, Abu Dhabi Investment Authority (one of the world's larger investment funds) declared losses of $\$ 125$ billion. Moreover, Dubai was bailed out after the property bust

\footnotetext{
23 The spike of the Divisia growth rate was likely driven by high oil prices in early to mid-2008.

24 Oman is not a member of the Organization of the Petroleum Exporting Countries (OPEC). Nevertheless, oil and other petroleum products continue to play a significant role in shaping the economy. For more information about the oil industry, see the statistical bulletins reported by the Omani Ministry of Oil and Gas.
} 
degraded the country's economic position. ${ }^{25}$ In addition to these factors, high inflation rates (above 12\%) have further imposed economic challenges upon the UAE monetary authorities. The most notable difference between Divisia and simple-sum indexes took place during 2006-2007 and 2009-2010. Those periods include the toughest economic challenges the UAE has faced (figure 2). However, the year-over-year growth rates for both indexes dropped sharply from $50 \%$ in 2008 to around 5\% in 2009. The rise in the monetary aggregates corresponds to the boom in oil prices during early 2008. Meanwhile, the following collapse of the aggregates' growth rates corresponds with the financial crises, which lowered global demand for oil, driving down the prices.

The behavioral patterns of the user-cost prices, aggregate interest rates, dual prices, and growth rates of the Divisia aggregate user-cost prices could be used as an "economic stability" indicator. User-cost prices often tend to go in different directions during periods of higher economic uncertainty [see Barnett, Fisher, and Serletis (1992)]. Our data seem to support this claim. Plots of the user-cost prices reveal that the user-cost prices of non-liquid monetary assets (e.g., savings and time deposits, and quasi-money) tend to be more volatile and unstable during financial crises as opposed to milder economic periods (figure 3). Moreover, the dual prices and growth rates of the broader Divisia user-cost aggregates are more volatile during times of economic uncertainty (figures 4 and 5). The aggregate interest rate of the narrow monetary aggregate, M1, is equal to zero for all GCC countries, except for Qatar, in which demand deposits yield positive interest rates. The aggregate interest rates corresponding to the broader monetary aggregate, M2, fluctuated the most during the recent financial crisis (figure 6). In 2011, aggregate interest rates remained below one percentage point as the GCC central banks set expansionary monetary policy to mitigate the effects of the recent financial crisis on Gulf economies.

25 Dubai has received a $\$ 10$ billion bail-out mostly from its neighbor state Abu Dhabi to enable Dubai to pay off the immediate debts of its most troubled state-run companies. 
Figure 3: User-cost (Rental) Prices of Monetary Assets
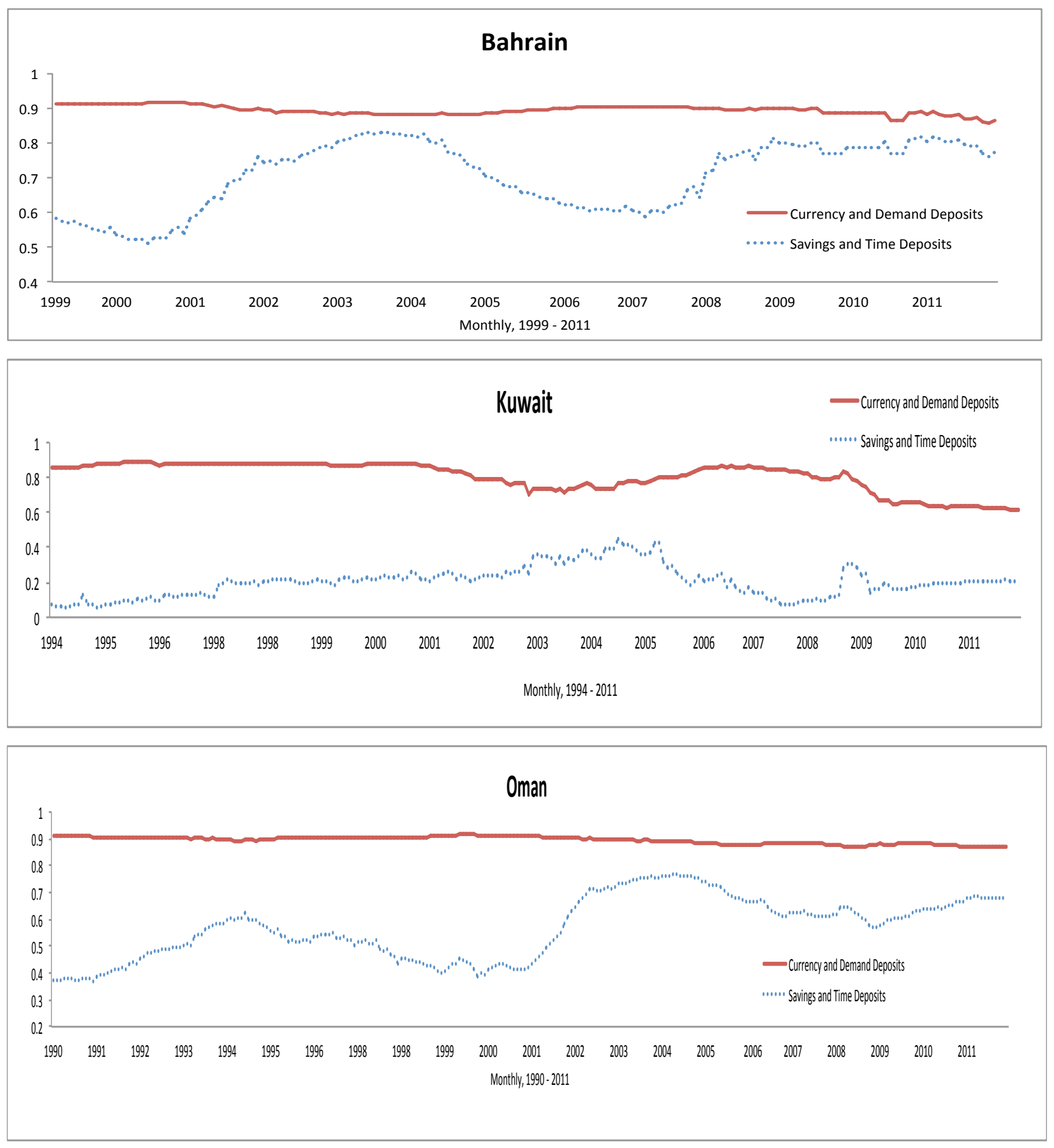

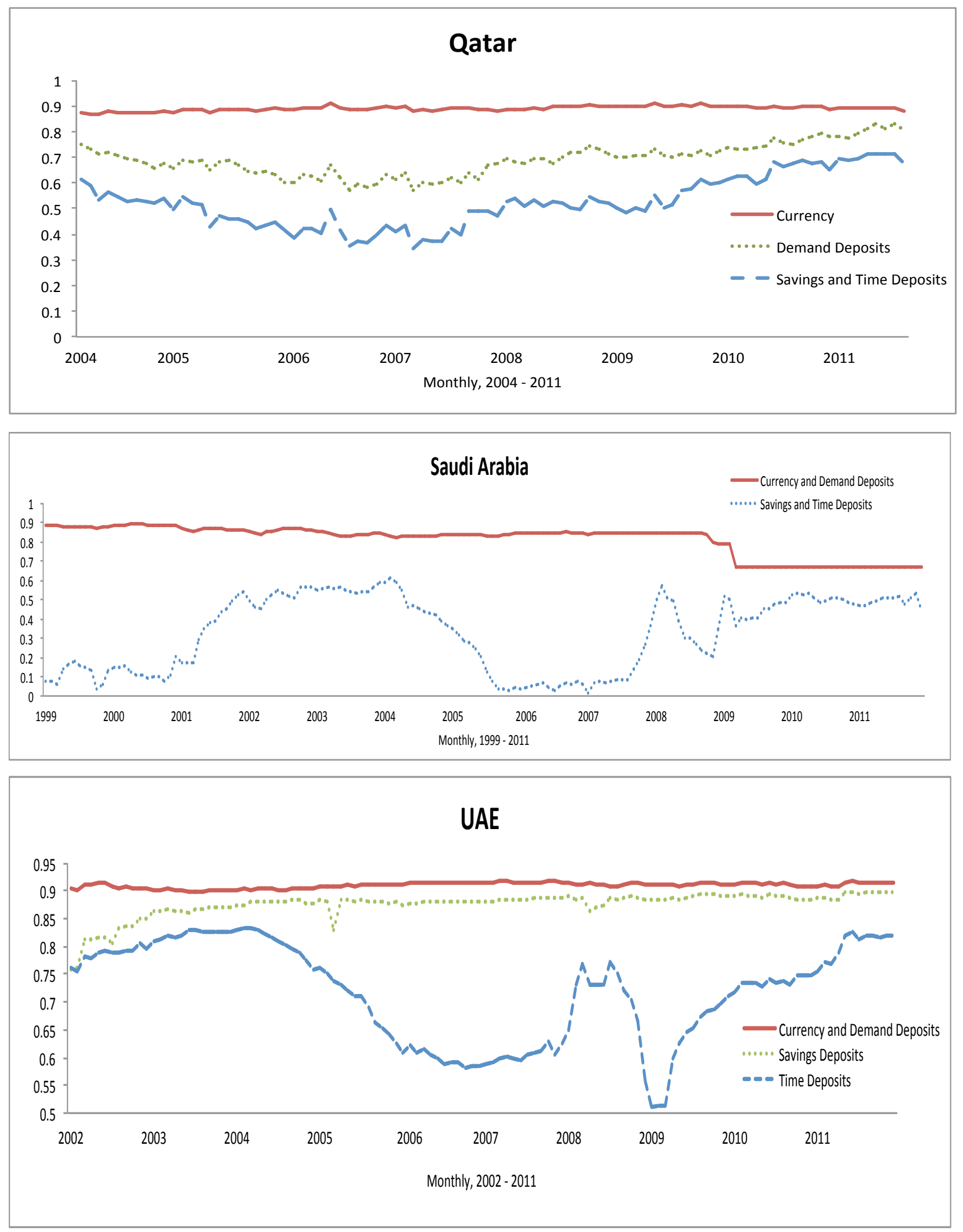
Figure 4: Monthly Growth Rates of the Divisia Aggregate User-Cost Prices for D1 and D2
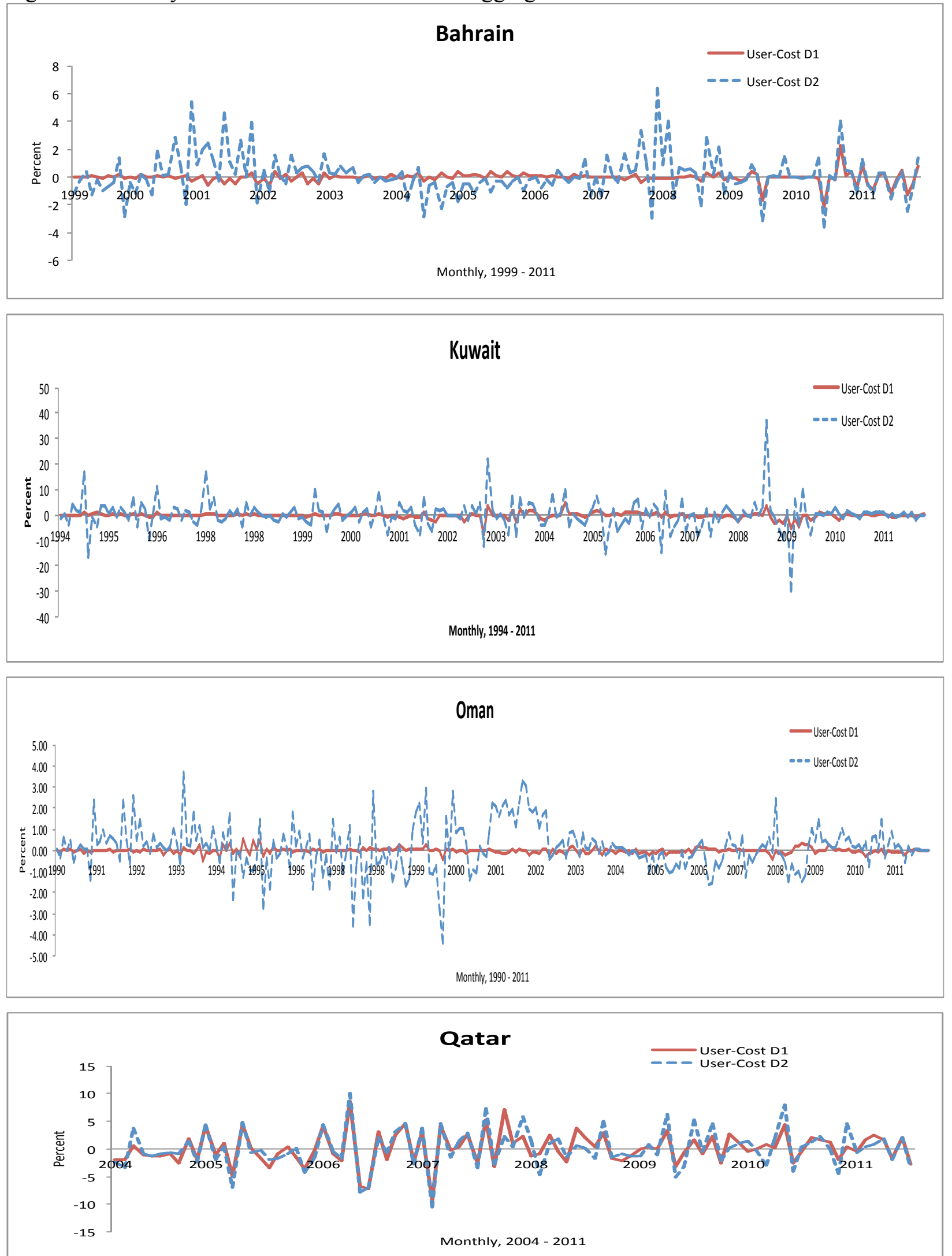

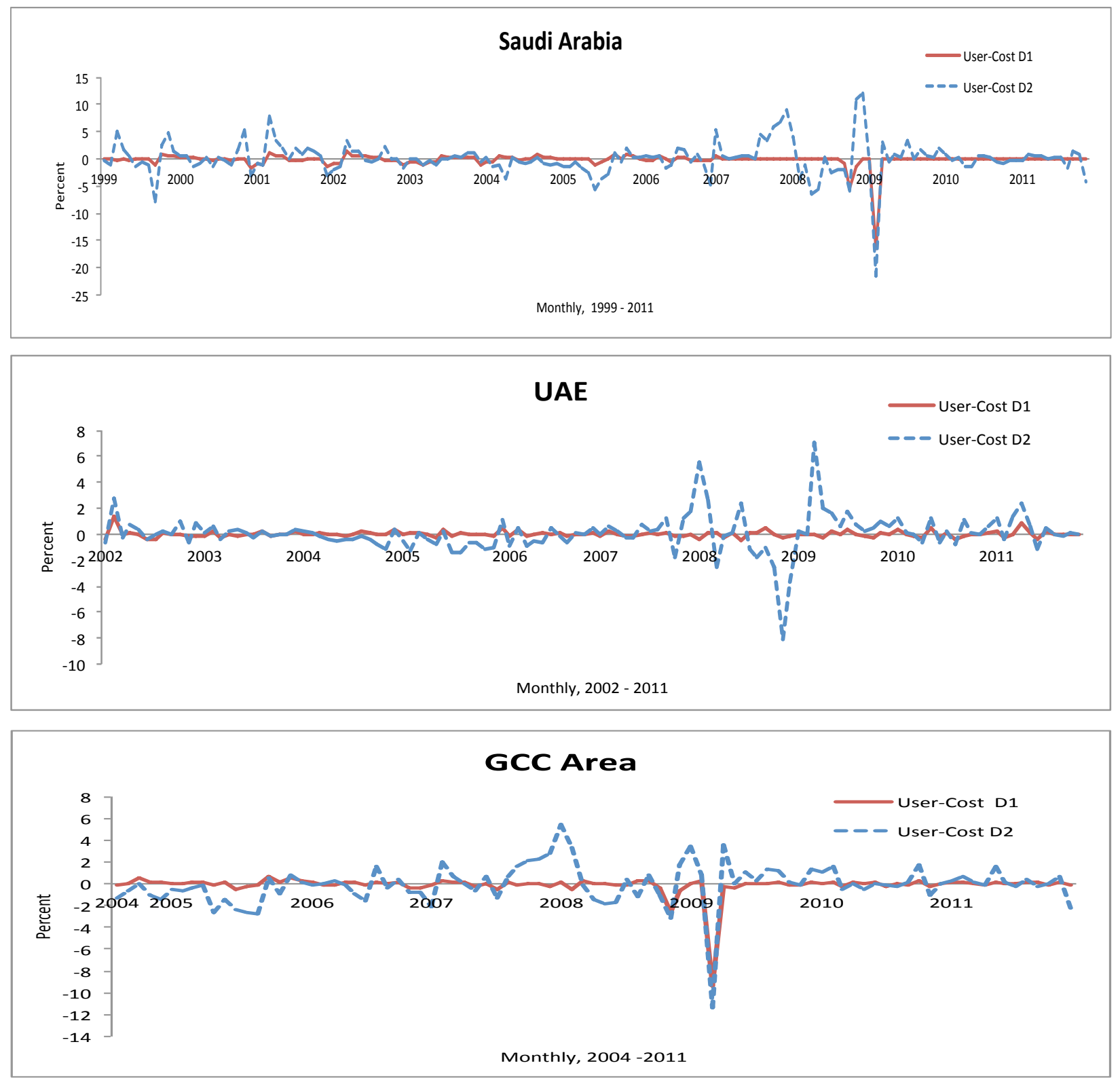
Figure 5: Dual Aggregate User-Cost Prices of the Divisia Monetary Aggregates D1 and D2 (normalized to 100 in the first year)
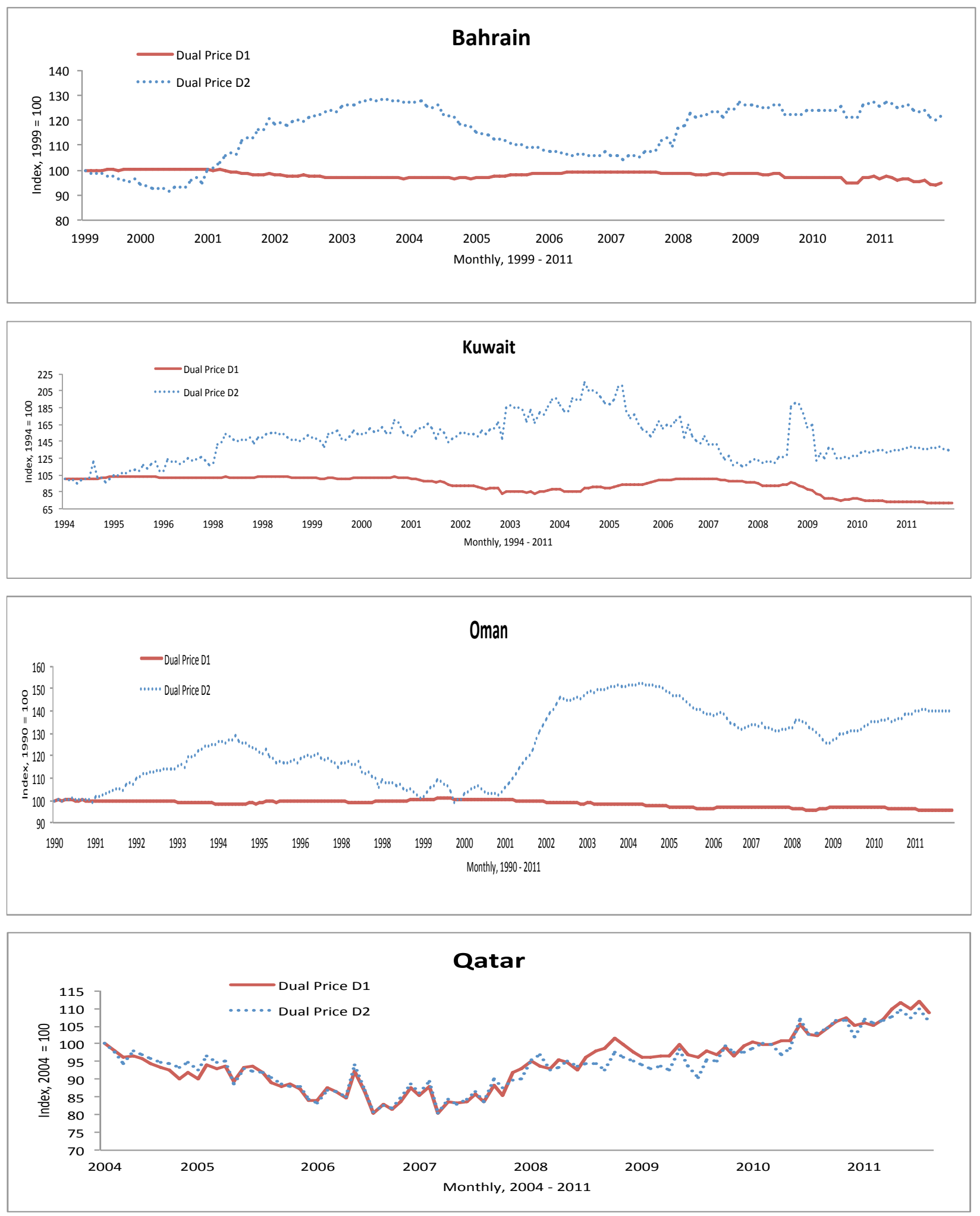

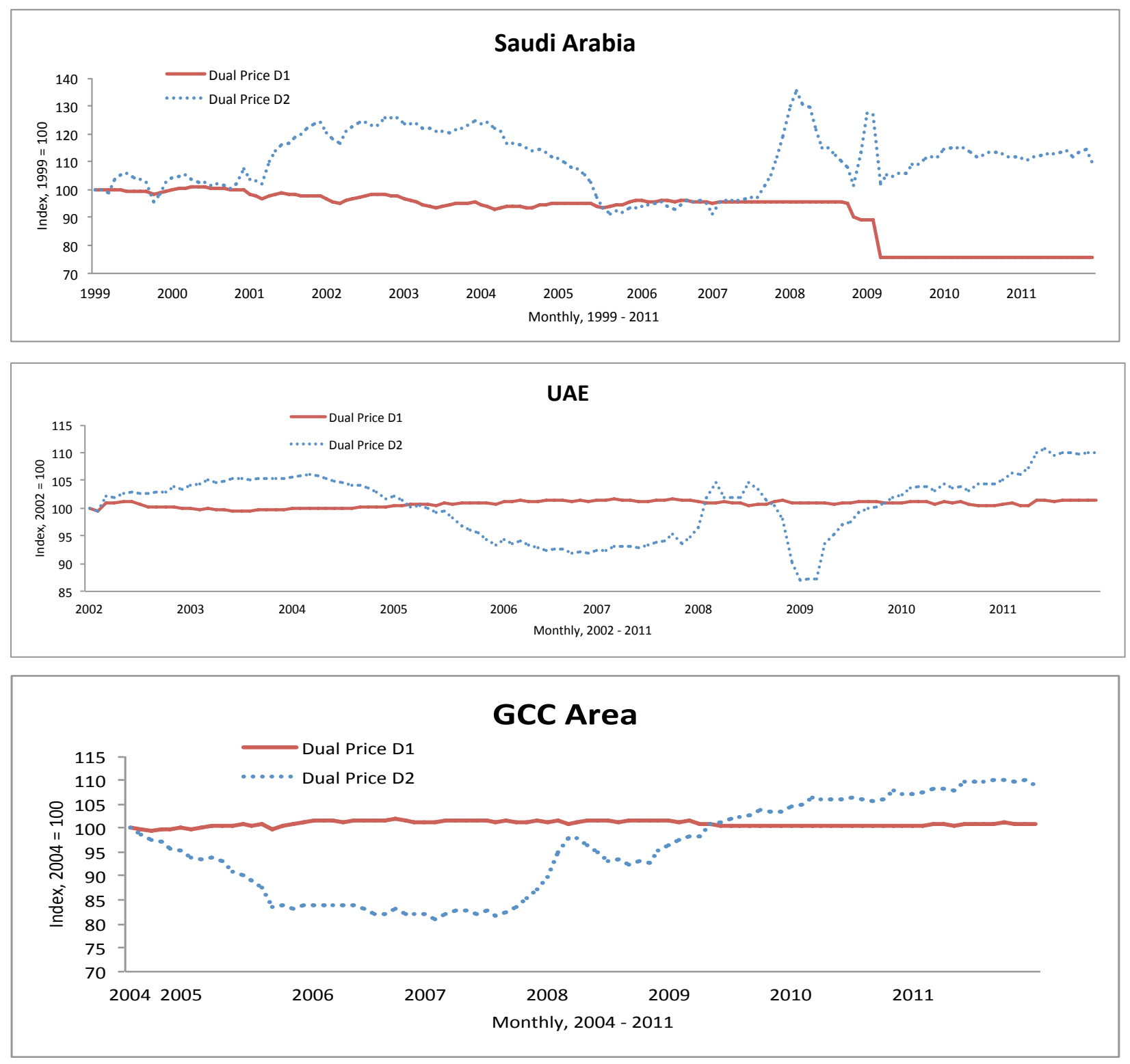
Figure 6: Annualized Interest Rate Aggregates Corresponding to Monetary Assets within M1and M2
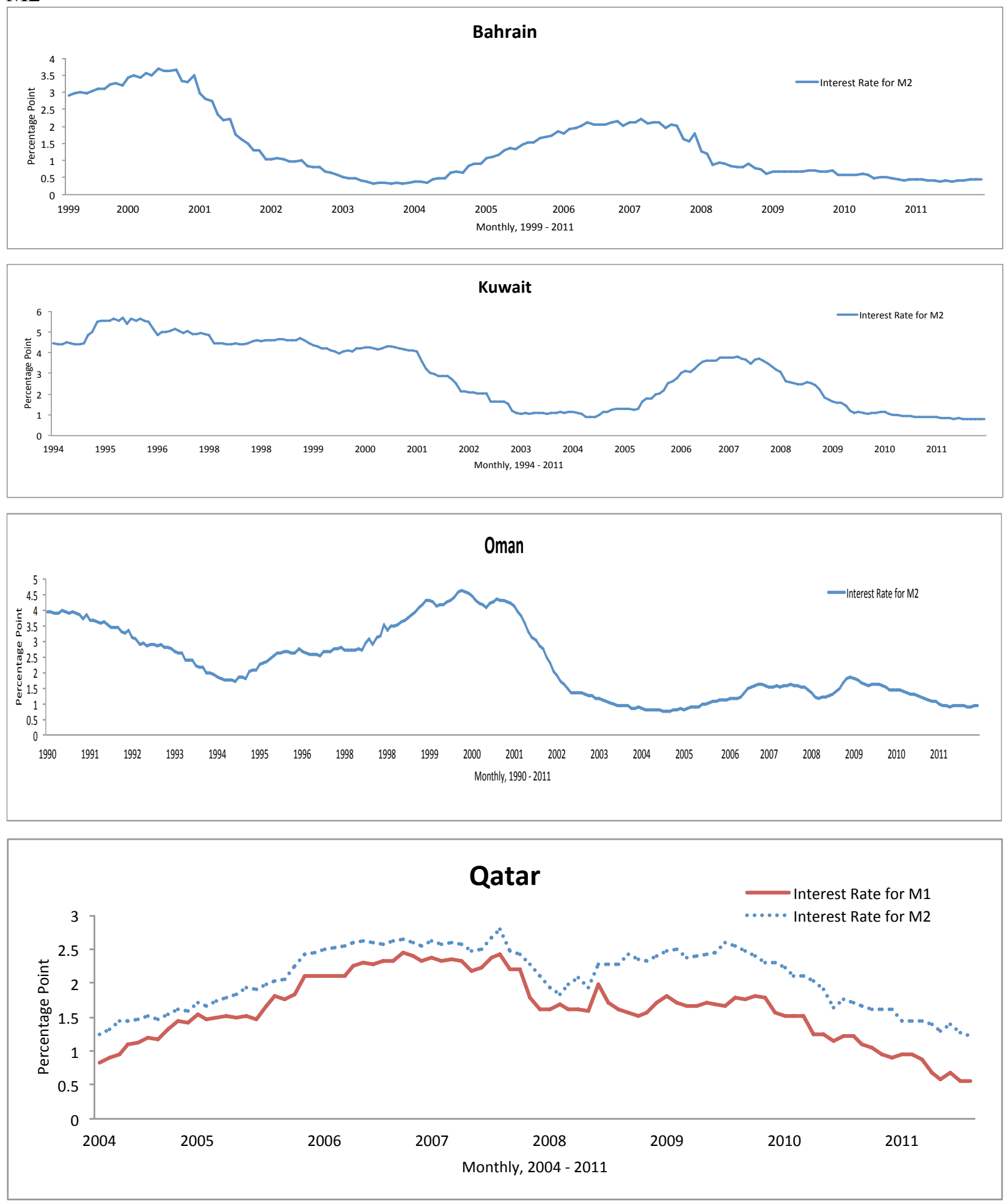

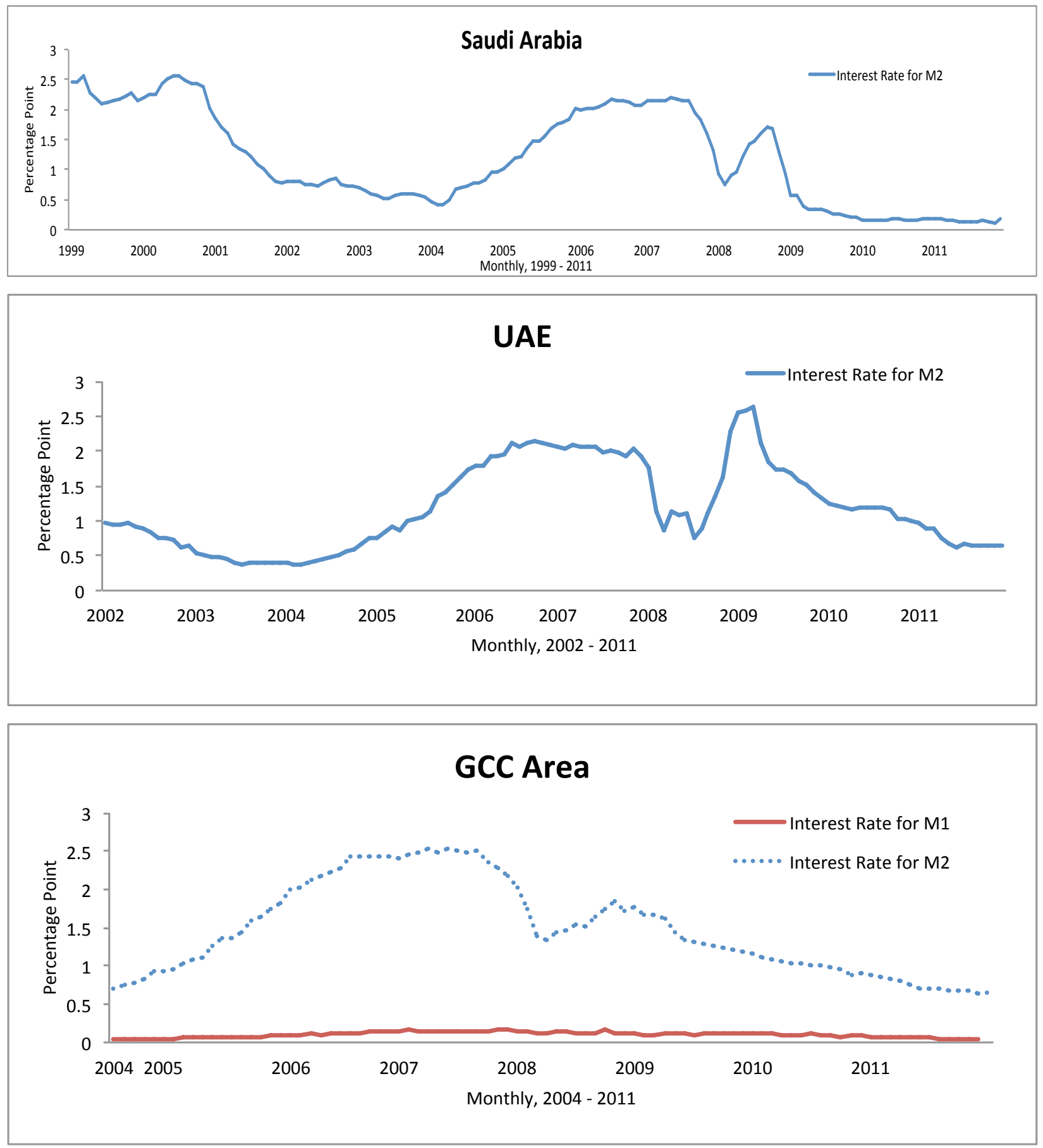


\subsection{Divisia Monetary Aggregates Over GCC Countries: A Heterogeneous Agents Approach}

There has been a recurring tendency toward higher economic integration among Gulf countries. Fueled by the increasing multilateral trade in the region, the Gulf Cooperation Council (GCC) has proposed its sentiment about launching a single monetary union, where indivisible monetary policies will be implemented simultaneously for all member states. Hence, the Gulf Monetary Council (GMC) was established in March 2010. Oman and UAE have opted out of the GMC for different reasons. In 2006, Oman withdrew from the monetary union, for which it has not met the convergence criteria required for joining the GMC. In 2009, UAE had a dispute over the location of the GMC being headquartered in Riyadh, the capital of Saudi Arabia. ${ }^{26}$ While negotiations are still ongoing, these factors have hindered the debut of the common currency for the Gulf area. In addition to these factors, the growing uncertainty about the world economy, and specifically the intensifying fears of the European sovereign debt crisis, have led the GMC to postpone its commencement of a common currency towards 2015.

Upon the completion of the common monetary policy in the Euro area, a large number of the studies in the monetary aggregation literature have used the following two approaches for measuring monetary service flows aggregated over the euro-zone: (i) the direct approach and (ii) the indirect approach. The former approach aggregates assets of a specific type over all countries by simply adding them up and then using the techniques provided by the Divisia index to obtain the overall monetary aggregate. The latter approach constructs Divisia aggregates across countries but uses ad hoc weighted averages (e.g., GDP weights) for the over-countries' aggregates. Barnett (2003) explained the drawbacks of these approaches: the direct approach requires very restrictive assumptions, whereas the indirect approach violates aggregation theory and does not produce nesting of the multilateral or unilateral representative agent approaches. Using ad hoc weighted averages of inflation rates over countries to produce a single inflation rate for the euro area is unsatisfactory and inconsistent with index number theory.

Barnett (1982) describes the phases that lead into optimal monetary aggregation in the

\footnotetext{
${ }^{26}$ UAE relentlessly demanded to be the host country for the GMC, since it has the second largest economy in the GCC area, after Saudi Arabia.
} 
following manner:

Stage 1: carefully determine the sets of monetary assets, such that the assets to be consolidated within an aggregate pass a separability test validating the grouping. This criterion implies that the sets of monetary assets are well-defined, based upon the statistical properties as well as the monetary services pertaining to these assets. ${ }^{27}$

Stage 2: Construct an index number formula from the superlative index number class for each admissible set of monetary assets acquired in stage 1. The Divisia index is not the only obtainable superlative index, but all index numbers in that class move closely together. ${ }^{28}$

Stage 3: Examine the interaction among the relevant macro-economic variables and the index numbers. This assessment can be carried out by means of empirical studies. The findings will determine optimal monetary aggregation.

Three increasingly restrictive approaches were developed by Barnett $(2003,2007)$ to capture the economic convergence dynamics evolving in the Euro zone. These approaches, starting from least restrictive approach, are: the heterogeneous agents approach, the multilateral representative agent approach, and the unilateral representative agent approach. The European Central Bank has benefited the most from this research in enhancing its Divisia monetary aggregates database provided to the ECB's Governing Council at its meetings.

In the following section, the Divisia monetary indexes are constructed over the GCC area. The findings suggest that while narrow monetary indexes are closely alike, the broad Divisia index outperforms its simple-sum counterpart. For the growth rates of the Divisia and simple-sum over the GCC countries, Divisia growth rates display business cycle patterns that are consistent with monetary policy.

A large portion of the present paper is based upon the seminal work done by Barnett (1979a;1979b;1980a,b), developed further by Barnett (2003,2007). In line with the heterogeneous agents approach proposed by Barnett $(2003,2007)$, we assume the existence of a representative consumer within countries in the Gulf union and treat the union's representative consumers as heterogeneous agents. This introduces us to a heterogeneous countries approach to aggregation

\footnotetext{
27 Weak-separability of the utility function is assumed in this paper. Many empirical studies provide tests for weak-separability. See, for example, Barnett and de Peretti (2009), Barnett and Choi (1989), Blackorby, Russell, and Primont (1998), de Peretti (2005, 2007), Fleissig and Whitney (2003, 2005), Swofford and Whitney (1987, 1994), and Varian (1982, 1983, and 1985). To our knowledge, Barnett and de Peretti (2009) offer the most promising test.

28 Fisher (1922) considered eleven superlative index numbers, including the Divisia index.
} 
over countries. Let $K$ be the number of countries in the Gulf monetary union.

In continuous time, let

$$
\begin{aligned}
& s_{\mathrm{k}}(\mathrm{t})=H_{k}(\mathrm{t}) / \sum_{k=1}^{K} H_{k}(\mathrm{t})=\text { country } k^{\prime} s \text { share of total GCC area population at time } t .{ }^{29} \\
& \mathrm{I}_{\mathrm{k}}=\mathrm{I}_{\mathrm{k}}(\mathrm{t})=\text { country } k^{\prime} s \text { total expenditure at time } t . \\
& e_{k t}=\text { country } k^{\prime} s \text { currency exchange rate against a market basket of currencies at } t .
\end{aligned}
$$

Consider a representative agent $h$ who lives in country $k \in\{1, \ldots, K\}$ with the utility function:

$$
U_{h}=U_{h}\left[u_{h}\left(\mathbf{m}_{h}^{*}\right), g_{h}\left(\mathbf{x}_{h}\right)\right]=U\left[u\left(\mathbf{m}_{h}^{*}, \phi_{h}\right), g\left(\mathbf{x}_{h}, \phi_{h}\right), \phi_{h}\right]
$$

for all tastes,$\phi_{h}$, in the Gulf area. ${ }^{30}$ While $U, u$, and $g$ are fixed functions, the corresponding functions $U_{h}, u_{h}$, and $g_{h}$ are random functions. ${ }^{31}$ Furthermore, assume that the representative agent, $h$, within country $k \in\{1, \ldots, K\}$ solves the following maximization problem for $\left(\mathbf{m}_{h}^{*}, \mathbf{x}_{h}\right)$ during period $t:^{32}$

$$
\begin{gathered}
\operatorname{maximize} U\left[u\left(\mathbf{m}_{h}^{*}, \phi_{h}\right), g\left(\mathbf{x}_{h}, \phi_{h}\right), \phi_{h}\right] \\
\text { subject to } \\
\mathbf{m}_{h}^{*^{\prime}} \boldsymbol{\pi}_{h}+\mathbf{x}_{h}^{\prime} \mathbf{p}_{h}=I_{h} .
\end{gathered}
$$

Define

$$
W_{k}=\frac{M_{k}^{*} \Pi_{k}^{*} p_{k}^{*} s_{k} e_{k}}{\sum_{k=1}^{K} M_{k}^{*} \Pi_{k}^{*} p_{k}^{*} s_{k} e_{k}}=\frac{M_{k} \Pi_{k}^{*} s_{k} e_{k}}{\sum_{k=1}^{K} M_{k} \Pi_{k}^{*} s_{k} e_{k}}=\frac{M_{k}^{*} \Pi_{k} s_{k} e_{k}}{\sum_{k=1}^{K} M_{k}^{*} \Pi_{k} s_{k} e_{k}}
$$

to be the $k^{\text {th }}$ country's expenditure share of the Gulf union's monetary service flow at time $t$.

\footnotetext{
${ }^{29} S_{k}$ is used to convert to per-capita values and we basically drop it to obtain total values.

30 The second equality is an immediate result of the assumption that differences in tastes across countries can be explained via a vector of taste-determining variables, $\phi_{h}$. See Barnett (2003) for more details.

31 Barnett $(2003,2007)$ rigorously explained the properties of these functions and their nested variables.

32 See Barnett $(2003,2007)$ for additional assumptions for the joint distribution of the random variables $\left(I_{h}, \mathbf{p}_{h}, e_{h}, \boldsymbol{\pi}_{h}, \phi_{h}\right)$ to exist.
} 
Similar to the share weight for single country, notice that $0 \leq W_{k} \leq 1$ and $\sum_{k=1}^{K} W_{k}=1$ are satisfied for the union's expenditure shares, so that we can treat $\left\{W_{1}, \ldots, W_{k}\right\}$ as a probability distribution for our Divisia indexes.

The Gulf area's nominal per-capita monetary services flow, $M$, real per-capita monetary services flow, $M^{*}$, nominal monetary user-cost price, $\Pi$, real monetary user-cost price, $\Pi^{*}$, and the Gulf area's Divisia Consumer Price Indexes, $p^{*}=p^{*}(t)$, and $P^{*}=P^{*}(t)$, are defined as follows, where there are two alternative ways of weighting inflation across countries: ${ }^{33}$

$$
\begin{aligned}
& \frac{d \log M}{d t}=\sum_{k=1}^{K} W_{k} \frac{d \log \left(M_{k} s_{k} e_{k}\right)}{d t} \\
& \frac{d \log M^{*}}{d t}=\sum_{k=1}^{K} W_{k} \frac{d \log \left(M_{k}^{*} s_{k}\right)}{d t} \\
& \frac{d \log \Pi}{d t}=\sum_{k=1}^{K} W_{k} \frac{d \log \left(\Pi_{k} e_{k}\right)}{d t} \\
& \frac{d \log \Pi^{*}}{d t}=\sum_{k=1}^{K} W_{k} \frac{d \log \left(\Pi_{k}^{*}\right)}{d t} \\
& \frac{d \log P^{*}}{d t}=\sum_{k=1}^{K} B_{k} \frac{d \log \left(p_{k}^{*} e_{k}\right)}{d t} \\
& \frac{d \log p^{*}}{d t}=\sum_{k=1}^{K} W_{k} \frac{d \log \left(p_{k}^{*} e_{k}\right)}{d t},
\end{aligned}
$$

where country k's expenditure share of Gulf consumption is

$$
B_{k}=\frac{X_{k} p_{k}^{*} e_{k}}{\sum_{k=1}^{K} X_{k} p_{k}^{*} e_{k}} .
$$

${ }^{33}$ Barnett (2003) proved the relationship between the nominal versus real variables hold, so that $\Pi=\Pi^{*} p^{*}$ and $M=M^{*} p^{*}$ 
The corresponding discrete time Divisia growth indexes for the GCC monetary union are:

$$
\begin{aligned}
& \log M_{t}-\log M_{t-1}=\sum_{k=1}^{K} W_{k t}^{*}\left(\log M_{k t} s_{k t} e_{k t}-\log M_{k, t-1} S_{k, t-1} e_{k, t-1}\right) \\
& \log M_{t}^{*}-\log M_{t-1}^{*}=\sum_{k=1}^{K} W_{k t}^{*}\left(\log M_{k t}^{*} s_{k t}-\log M_{k, t-1}^{*} s_{k, t-1}\right) \\
& \log \Pi_{t}-\log \Pi_{t-1}=\sum_{k=1}^{K} W_{k t}^{*}\left(\log \Pi_{k t} e_{k t}-\log \Pi_{k, t-1} e_{k, t-1}\right) \\
& \log \Pi_{\mathrm{t}}^{*}-\log \Pi_{t-1}^{*}=\sum_{k=1}^{K} W_{k t}^{*}\left(\log \Pi_{k t}^{*}-\log \Pi_{k, t-1}^{*}\right) \\
& \log P_{t}^{*}-\log P_{t-1}^{*}=\sum_{k=1}^{K} B_{k t}^{*}\left(\log p_{k t}^{*} e_{k t}-\log p_{k, t-1}^{*} e_{k, t-1}\right), \\
& \log p_{t}^{*}-\log p_{t-1}^{*}=\sum_{k=1}^{K} W_{k t}^{*}\left(\log p_{k t}^{*} e_{k t}-\log p_{k, t-1}^{*} e_{k, t-1}\right),
\end{aligned}
$$

where $W_{k t}^{*}=(1 / 2)\left(W_{k t}+W_{k, t-1}\right)$ and $B_{k t}^{*}=(1 / 2)\left(B_{k t}+B_{k, t-1}\right)$.

In levels, the nominal and real per-capita Divisia monetary indexes, respectively, are

$$
\frac{M_{t}}{M_{t-1}}=\prod_{k=1}^{K}\left(\frac{M_{k t} s_{k t} e_{k t}}{M_{k, t-1} s_{k, t-1} e_{k, t-1}}\right)^{W_{k t}^{*}}
$$

and

$$
\frac{M_{t}^{*}}{M_{t-1}^{*}}=\prod_{k=1}^{K}\left(\frac{M_{k t}^{*} s_{k t}}{M_{k, t-1}^{*} s_{k, t-1}}\right)^{W_{k t}^{*}} .
$$

Observe that Fisher's factor reversal property holds for the monetary quantity and user-cost aggregates over countries. The total expenditure on monetary services aggregated over countries would be the same, whether obtained by multiplying the monetary union's quantity by its user-cost aggregates or by the sum of the products within countries [see Barnett (2003) for a complete proof]. This result leads to Fisher's factor reversal test for the Gulf area:

$$
M_{t}^{*} \Pi_{t}=\sum_{k=1}^{K}\left(M_{k t}^{*} \Pi_{k t} s_{k t} e_{k t}\right)
$$


Given the above relation, the price dual to the Gulf area Divisia monetary aggregates could be easily computed by dividing expendure by the Gulf monetary aggregate, $M^{*}$, so that

$$
\Pi_{t}=\frac{\sum_{k=1}^{K}\left(M_{k t}^{*} \Pi_{k t} s_{k t} e_{k t}\right)}{M_{t}^{*}}
$$

Analogously to the within country case, the aggregate interest rate for the GCC monetary union is:

$$
\tilde{R}_{t}=\frac{\sum_{k=1}^{K}\left(\sum_{(j, i) \in S_{k}} m_{k j i t}\right) \tilde{R}_{k t} e_{k t}}{\sum_{k=1}^{K}\left(\sum_{(j, i) \in S_{k}} m_{k j i t}\right) e_{k t}}=\frac{\sum_{k=1}^{K}\left(\sum_{(j, i) \in S_{k}} r_{k j i t} m_{k j i t}\right) e_{k t}}{\sum_{k=1}^{K}\left(\sum_{(j, i) \in S_{k}} m_{k j i t}\right) e_{k t}} .
$$

Figures 1 and 2 depict the year-over-year growth rates of the Divisia and simple-sum aggregated over the GCC countries. The narrow monetary Divisia growth rates for the GCC union are equivalent to their counterpart simple-sum indexes --- as is the case for each single country (figure 1). The Divisia growth rates of the broad monetary aggregates differ from the simple-sums (figure 2). The year-over-year Divisia growth rates remarkably exemplify the business cycles, during which the growth rates are high in the economic boom -- fueled by large oil revenues and massive government spending on infrastructure projects --- and low afterwards, in periods when oil prices dropped sharply as a consequence of the distress over the global economy. Figure 2 shows that the hump-shaped Divisia year-over-year growth rates are more evident than the simple-sum's. Specifically, Divisia year-over-year growth rates have outreached the simple-sum's. Divisia growth was below simple sum's during recessions, while above throughout expansionary phases. The findings suggest that the Gulf monetary council, if guided by the simple sum, may overreact by implementing an excessive contractionary/expansionary policy, when it is not needed.

Figure 7 depicts the annual Divisia inflation rate versus the arithmetic average inflation rate. At the beginning of the recent financial crises, the Divisia inflation rate diverged from its counterpart and remained relatively higher than the arithmetic average inflation rate. Since the inflation rate would be underestimated under the arithmetic average inflation rate, the GMC monetary policy would be based upon misleading data, if the GMC were to use the arithmetic average price index, as would be philosophically consistent with the simple-sum approach to 
aggregation over imperfect substitutes. 
Figure 7: Annual Inflation Rates

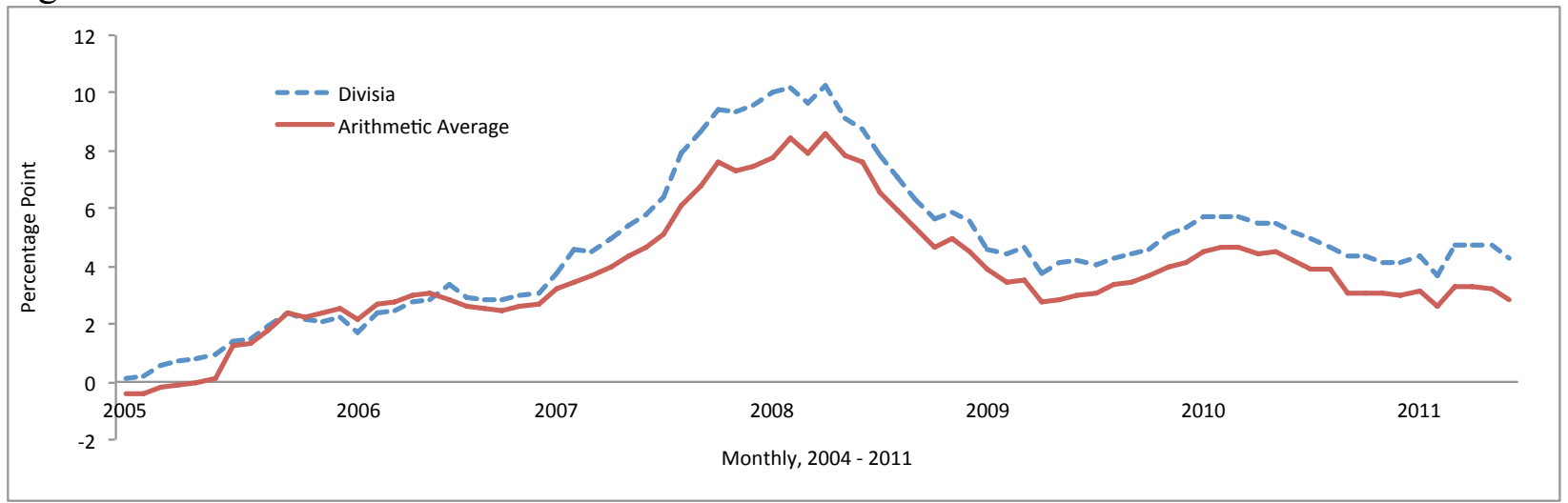

The user-cost prices, aggregate interest rates, and growth rates of the Divisia aggregate user-cost prices may serve as economic stability indicator for the GCC area. A high (low) variation of these growths over time is associated with high (low) economic uncertainty. Figures 4,5, and 6 indicate that the aggregate interest rates, dual prices, and the growth rates of Divisia aggregate user-cost prices of the broader Divisia aggregates for the GCC area are more volatile than the narrow aggregtes during the recent financial crises. The findings suggest a high correlation between the broad monetary aggregates and the world economy. Moreover, Divisia monetary aggregates provide critical information about inside liquidity created by financial intermediaries. In the aftermath of financial crises, the narrow aggregates were growing, while simultaneously the broad aggregates plunged, indicating the shortfall of financial intermediaries in creating inside money (figures 1 and 2).

\section{Divisia Second Moments and the Distribution Effects}

We have seen the major role of Divisia growth means in constructing the Divisia monetary aggregates. We extend our analyses further to the Divisia second moments. Divisia variances measure the degree to which monetary policy affects countries differently within a union. Exploiting the Divisia second moments is of particular importance, especially to the GMC [see Barnett (2003)]. Our GCC Divisia variances capture the distribution effects within Gulf countries and simultaneously measure the progress made towards monetary and financial convergence. Providing the Divisia second moments can not only help to identify the distribution effects of the single monetary policy, but can also supply the GMC with additional tools to gauge 
the dynamics of monetary policy. ${ }^{34}$

Let $X_{k}=g_{k}\left(\boldsymbol{x}_{k}\right)$ be the within-country, consumer-goods, per-capita aggregates. As above, define country $k$ 's expenditure share of the Gulf consumption by:

$$
B_{k}=\frac{X_{k} p_{k}^{*} e_{k}}{\sum_{k=1}^{K} X_{k} p_{k}^{*} e_{k}}
$$

and define

$$
d \log W=\sum_{k=1}^{K} W_{k} d \log W_{k}
$$

The Divisia growth rate variances computed about their means, across the Gulf countries, are defined as:

$$
\begin{aligned}
& \boldsymbol{\Omega}=\sum_{k=1}^{K} W_{k}\left[d \log \left(M_{k} s_{k} e_{k}\right)-d \log M\right]^{2} \\
& \Omega^{*}=\sum_{k=1}^{K} W_{k}\left[d \log \left(M^{*}{ }_{k} s_{k}\right)-d \log M^{*}\right]^{2} \\
& \Phi=\sum_{k=1}^{K} W_{k}\left[d \log \left(\Pi_{k} e_{k}\right)-d \log \Pi\right]^{2} \\
& \boldsymbol{\Phi}^{*}=\sum_{k=1}^{K} W_{k}\left[d \log \left(\Pi_{k}^{*}\right)-d \log \Pi^{*}\right]^{2} \\
& \Psi=\sum_{k=1}^{K} W_{k}\left[d \log \left(W_{k}\right)-d \log W\right]^{2} \\
& \Gamma_{M}=\sum_{k=1}^{K} W_{k}\left[d \log \left(p_{k}^{*} e_{k}\right)-d \log p^{*}\right]^{2} \\
& \Gamma=\sum_{k=1}^{K} B_{k}\left[d \log \left(p_{k}^{*} e_{k}\right)-d \log P^{*}\right]^{2}
\end{aligned}
$$

where $\Omega$ and $\Omega^{*}$ are the Divisia monetary services growth rate variances in nominal and real

34 By connecting user-cost and monetary service growth rates, Barnett (2003) provided an additional measure of the effectiveness of transmission mechanisms that operate through interest rates. Since the GMC monetary policy is committed to the de facto pegging of its exchange rate to the US dollar, rather than operating through interest rates, we preclude interest rate indicators from our study. 
terms, respectively. Similarly, $\Phi$ and $\Phi^{*}$ are the Divisia aggregate user-cost growth rate variances, while $\Psi$ is the growth rate variance of the Divisia monetary services expenditure-share. Lastly, $\Gamma_{M}$ and $\Gamma$ denote the Divisia inflation variances, with the alternative weighting methods, one based on consumption sector weighting and the other based on monetary sector weighting. The indexes $\Omega$ and $\Omega^{*}$ are measures of the dispersion of monetary growth rates across GCC countries in nominal terms, whereas $\Psi$ is the measure in real terms. Moreover, $\Gamma$ and $\Gamma_{M}$ are measures of the dispersion of the GCC inflation rates. ${ }^{35}$ The Divisia aggregate user-cost growth rate variances, $\Phi$ and $\Phi^{*}$, indicate the progress of synchronization in the financial markets of the GCC countries. The values of $\Omega, \Omega^{*}, \Psi, \Gamma_{M}$ , and $\Gamma$ measure the distribution effects of the GMC monetary policy over the GCC area.

Interestingly, decreasing values of $\Omega, \Omega^{*}, \Psi$, and $\Gamma$ indicators of economic harmonization among GCC countries and more uniform effects of monetary policy over the GCC countries. These indicators can be used not only to monitor the progress of harmonization over the GCC economies, but also to serve as a measure of the monetary policy's effects across the Gulf area.

Excluding the effects of the recent financial crisis, the variances of the monetary services and expenditure share growth rates of the GCC area suggest that the GCC countries have been highly synchronized (figures 8 and 9). Figure 10 shows that the Divisia aggregate user-cost growth rate variances have been consistently low, with the exception of 2008 and 2009. More importantly, the growth rate variances, $\Phi$, of the Divisia aggregate user cost have remained close to zero, implying that the financial markets have become even more synchronized recently. The Divisia inflation rate variances fluctuate over time from being high during periods of economic unrest to being low in times of economic prosperity (figure 11). The high variances are, respectively, associated with periods of meltdown of the Saudi stock markets, global financial crises, and Arab Spring uprisings in Bahrain.

35 See Barnett $(2003,2007)$ for more details. 
Figure 8: Divisia Monetary Services Growth Rate Variances, $\Omega$, of D1 and D2

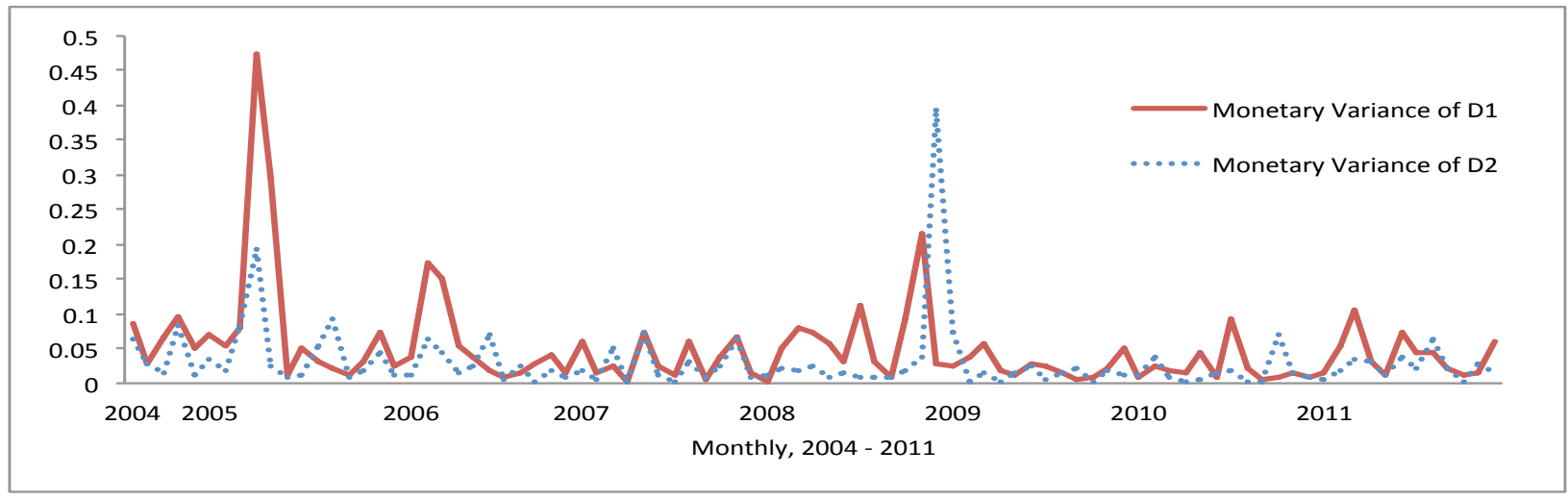

Figure 9: Divisia Monetary Services Expenditure-Share Growth Rate Variances, $\Psi$, of D1 and D2

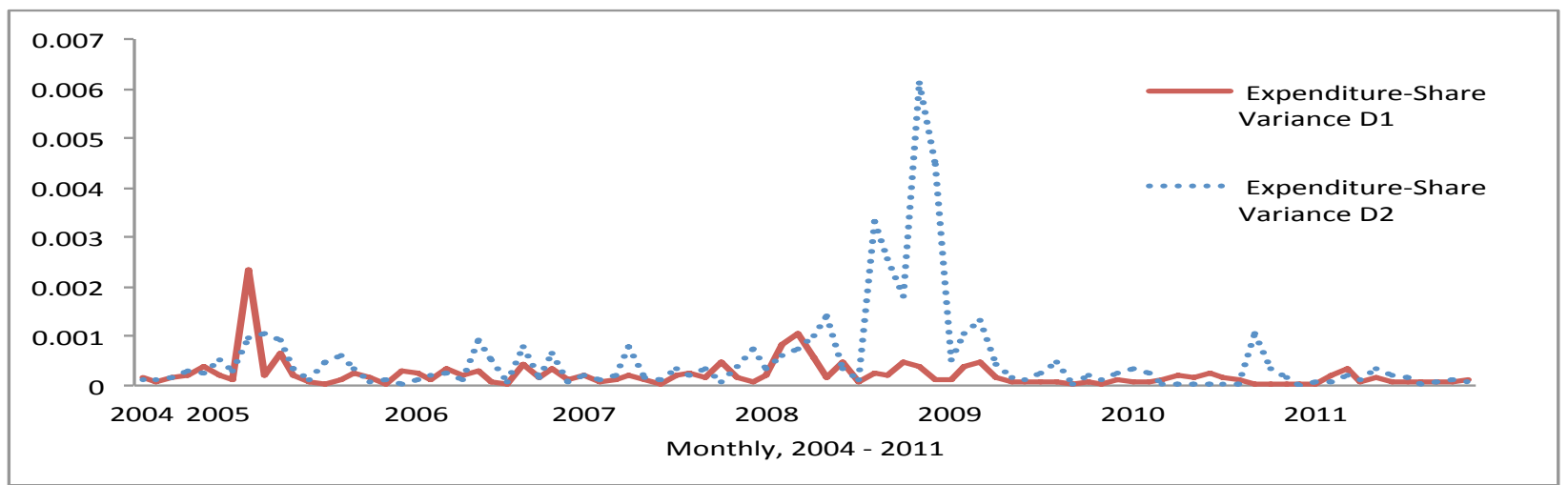


Figure 10: Divisia Aggregate User-Cost Growth Rate Variances, $\Phi$, of D1 and D2

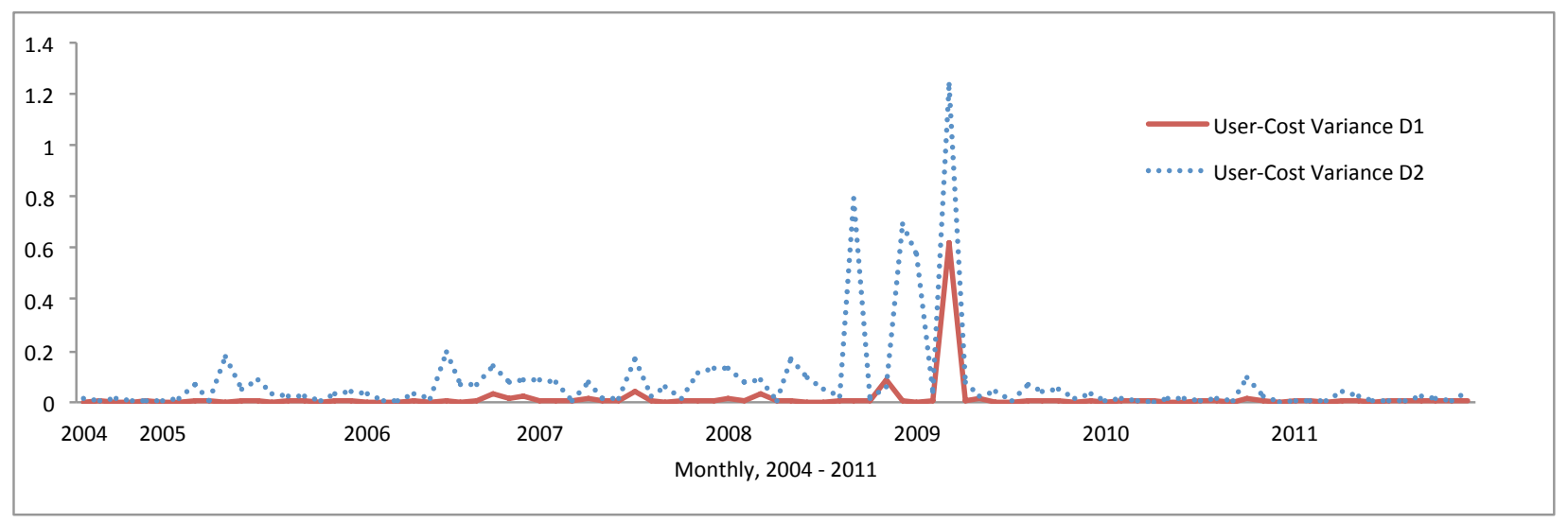

Figure 11: Divisia Inflation Rate Variances, $\Gamma_{M}$, of D1 and D2

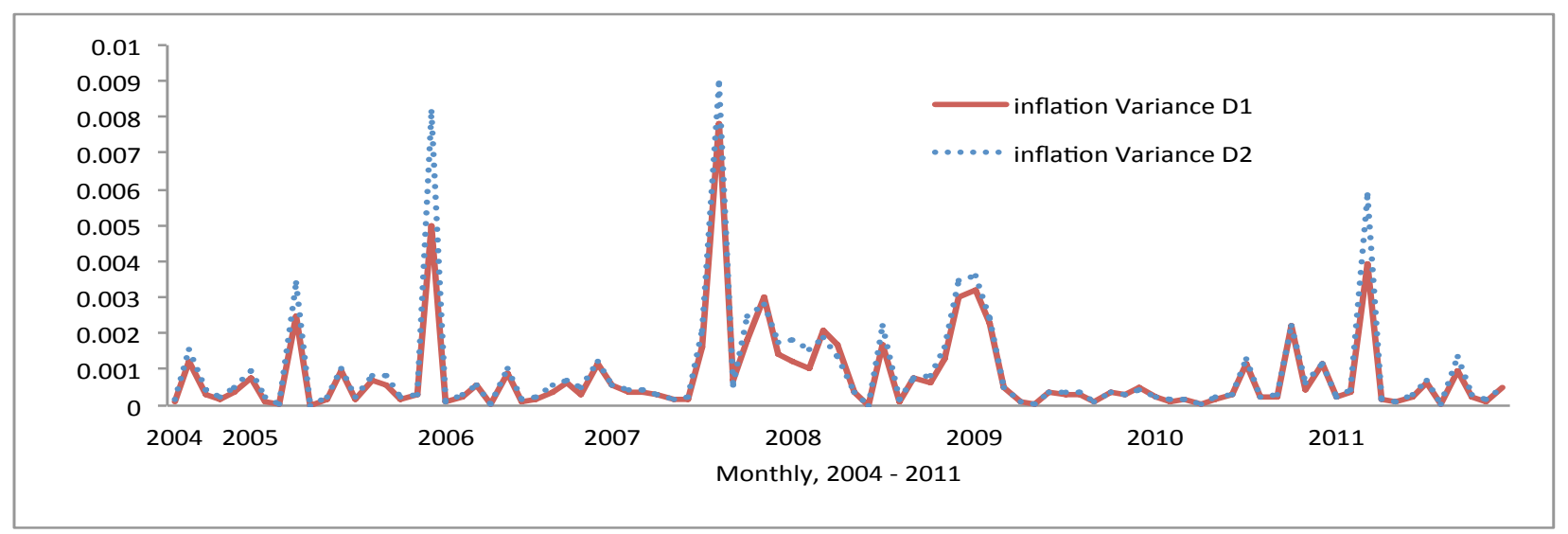

\section{Conclusion}

It is a well-known fact that the broader the monetary aggregate, the more obvious the deficiency of the simple-sum index in measuring the amount of money services injected into the economy. The implicit assumption made when using simple-sum monetary aggregates is that all components are perfect one-for-one substitutes in producing liquidity services. Broad aggregates, which group currency with government bonds, will certainly fail to satisfy this assumption. At broad levels of aggregation, simple-sum measures can be very misleading and diverge from the properly weighted Divisia aggregates.

The major drawback of the officially published simple-sum monetary aggregates is its lack of theoretical foundations. For monetary policy to be more effective, the policymaker's 
decisions should be based upon data with valid economic meaning (i.e., computed by techniques developed in the fields of aggregation and index number theory). A key property of the Divisia index lies in its compatibility with microeconomic aggregation theory.

In 1980, Barnett originated the Divisia monetary aggregates for the United States. The number of central banks and financial organizations employing the Divisia indexes has been growing since then. Building the Divisia monetary indexes for the Gulf area can facilitate transforming the GCC central banks to be among the leading central banks maintaining Divisia monetary aggregates.

Using the heterogeneous agents approach to aggregation over countries, based on Theil (1967) and Barnett (1979a,b; 1980a,b) and developed further in Barnett (2003, 2007), we construct the Divisia monetary index for the GCC area. Our findings confirm the dominance of the Divisia indexes in displaying a business cycle pattern that is consistent with GCC monetary policy. Specifically, Divisia monetary growth rates are low prior to recessions, while those growth rates increase at a faster pace than simple-sum during recoveries.

Moreover, we explore the distribution effects of policy within the GCC monetary union and examine the progress towards economic convergence by utilizing Divisia second moments. The results indicate that monetary policy for GCC countries are highly synchronized. Hence a common GCC monetary policy will have a uniform effect over member countries. In addition, there is direct evidence of progress towards harmonization of financial markets over GCC countries.

We propose an economic stability indicator for the GCC area, by analyzing the dynamics pertaining to certain variables such as the dual price aggregate, aggregate interest rates, and the growth rates of Divisia aggregate user-cost. High variation of these variables over time is a sign of high economic uncertainty and vice versa. Our indicator performs well in detecting periods of economic distress, namely the recent financial crises. 


\section{References}

Alsahafi, Mamdooh. "Linear and Non-Linear Techniques for Estimating the Money Demand Function: The Case of Saudi Arabia." 3378928, University of Kansas (2009).

Barnett, William A."The User Cost of Money." Economics Letters 1, no. 2 (1978): 145-49.

Barnett, William A."The Joint Allocation of Leisure and Goods Expenditure." Econometrica 47, no. 3 (1979a): 539-63.

Barnett, William A."Theoretical Foundations for the Rotterdam Model." Review of Economic Studies 46, no. 1 (1979b): 109-30.

Barnett, William A. "Economic Monetary Aggregates--Reply." Journal of Econometrics 14, no. 1 (1980a): 57-59.

Barnett, William A."Economic Monetary Aggregates an Application of Index Number and Aggregation Theory." Journal of Econometrics 14, no. 1 (1980b): 11-48.

Barnett, W.A. Consumer Demand and Labor Supply: Goods, Monetary Assets, and Time. Elsevier, Amsterdam (1981a).

Barnett, William A."The New Monetary Aggregates: A Comment." Journal of Money, Credit and Banking 13, no. 4 (1981b): 485-89.

Barnett, William A."The Optimal Level of Monetary Aggregation." Journal of Money, Credit and Banking 14, no. 4 (1982): 687-710.

Barnett, W.A."The Microeconomic Theory of Monetary Aggregation." New Approaches to Monetary Economics, Cambridge U. Press, Cambridge, UK (1987).

Barnett, William A. "Aggregation-Theoretic Monetary Aggregation over the Euro Area, When Countries Are Heterogeneous." EconWPA (2003).

Barnett, William A."Multilateral Aggregation-Theoretic Monetary Aggregation over Heterogeneous Countries." Journal of Econometrics 136, no. 2 (2007): 457-82.

Barnett, W.A. Getting It Wrong: How Faulty Monetary Statistics Undermine the Fed, the Financial System, and the Economy. MIT Press, Boston (2012).

Barnett, William A., and Marcelle Chauvet. "How Better Monetary Statistics Could Have Signaled the Financial Crisis." Journal of Econometrics 161, no. 1 (2011a): 6-23.

Barnett, William, A. and Marcelle Chauvet. Financial Aggregation and Index Number Theory. World Scientific Books. Vol. 2: World Scientific Publishing Co. Pte. Ltd. (2011b).

Barnett, William A. and Seungmook Choi. "A Monte Carlo Study of Tests of Blockwise Weak Separability." Journal of Business \& Economic Statistics 7, no. 3 (1989): 363-77.

Barnett, William A. and Philippe de Peretti. "Admissible Clustering of Aggregator Components: A Necessary and Sufficient Stochastic Semi-Nonparametric Test for Weak Separability."Macroeconomic Dynamics 13, supplement 2 (2009): 317-334.

Barnett, William A., Douglas Fisher, and Apostolos Serletis. "Consumer Theory and the Demand for Money." Journal of Economic Literature 30, no. 4 (1992): 2086-119.

Barnett, W.A., E.K. Offenbacher, and P.A. Spindt." The New Divisia Monetary Aggregates." The Journal of Political Economy 92, no. 6 (1984): 1049.

Beyer, A., J. A. Doornik, and D. F. Hendry. "Constructing Historical Euro-Zone Data." European University Institute (2000).

Binner, Jane M., Rakesh K. Bissoondeeal, Thomas Elger, Alicia M. Gazely, and Andrew W. 
Mullineux. "A Comparison of Linear Forecasting Models and Neural Networks: An Application to Euro Inflation and Euro Divisia." Applied Economics 37, no. 6 (2005): 665-80.

Binner, Jane M., Rakesh K. Bissoondeeal, C. Thomas Elger, Barry E. Jones, and Andrew W. Mullineux. "Admissible Monetary Aggregates for the Euro Area." Journal of International Money and Finance 28, no. 1 (2009): 99-114.

Binner, Jane M., Alicia M. Gazely, Graham Kendall. "Evaluating the Performance of a Eurodivisia Index Using Artificial Intelligence Techniques." International Journal of Automation and Computing 5, no. 1 (2008): 58-62.

Blackorby, C., Russell, R.R. and D. Primont. "Separability: A Survey ". In: S. Barbera, P. Hammond, and C. Seidl, eds, The Handbook of Utility Theory, Kluwer, Dordrecht. vol. 1 (1998): 49-92.

de Peretti, Philippe. "Testing the Significance of the Departures from Utility Maximization." Macroeconomic Dynamics 9, no. 03 (2005): 372-97.

de Peretti, Philippe. "Testing the Significance of the Departures from Weak Separability." International Symposia in Economic Theory and Econometrics: Functional Structure Inference, William Barnett and Apostolos Serletis, Eds., Elsevier, Amsterdam. (2007).

Diewert, W. E. "Exact and Superlative Index Numbers." Journal of Econometrics 4, no. 2 (1976): 115-45.

Fisher, I. The Making of Index Numbers: A Study of Their Varieties, Tests, and Reliability. Houghton Mifflin Company, Boston (1922).

Fleissig, Adrian R., and Gerald A. Whitney. "A New Pc-Based Test for Varian's Weak Separability Conditions." Journal of Business \& Economic Statistics 21, no. 1 (2003): 133-44.

Fleissig, A. R. and Gerald A. Whitney. "Testing for the Significance of Violations of Afriat's Inequalities,." Journal of Business \& Economic Statistics, Vol. 23, no. No. 3, (2005): 355 62.

Hancock, Matthew. "Divisia Money." Bank of England Quarterly Bulletin. (2005).

Klein, Benjamin. "Competitive Interest Payments on Bank Deposits and the Long-Run Demand for Money." American Economic Review 64, no. 6 (1974): 931-49.

Reimers, Hans-Eggert. "Analysing Divisia Aggregates for the Euro Area." Deutsche Bundesbank, Research Centre (2002).

Startz, Richard. "Implicit Interest on Demand Deposits." Journal of Monetary Economics 5, no. 4 (1979): 515-34.

Stracca, Livio. "Does Liquidity Matter? Properties of the Synthetic Divisia Monetary Aggregate in the Euro Area." European Central Bank (2001).

Swofford, James L., and Gerald A. Whitney. "Nonparametric Tests of Utility Maximization and Weak Separability for Consumption, Leisure and Money." The Review of Economics and Statistics 69, no. 3 (1987): 458-64.

Swofford, James L., and Gerald A. Whitney."A Revealed Preference Test for Weakly Separable Utility Maximization with Incomplete Adjustment." Journal of Econometrics 60, no. 1-2 (1994): 235-49.

Theil, H. Economics and Information Theory. Elsevier, Amsterdam (1967).

Törnqvist, L. "The Bank of Finland's Consumer Price Index." Bank of Finland Review 10, no. 1-8 (1936). 
Varian, Hal R."The Nonparametric Approach to Demand Analysis." Econometrica 50, no. 4 (1982): 945-73.

Varian, Hal R."Non-Parametric Tests of Consumer Behaviour." Review of Economic Studies 50, no. 1 (1983): 99-110.

Varian, Hal R. "Non-Parametric Analysis of Optimizing Behavior with Measurement Error." Journal of Econometrics 30, no. 1-2 (1985): 445-58.

Woodford, Michael. Interest and Prices: Foundations of a Theory of Monetary Policy. Princeton University Press, Princeton. (2003). 